\title{
All-Perovskite Tandem Solar Cells: A Roadmap to Uniting High Efficiency with High Stability
}

\author{
Xiaopeng Zheng," Abdullah Y. Alsalloum," Yi Hou, Edward H. Sargent,* and Osman M. Bakr*
}

Cite This: https://dx.doi.org/10.1021/accountsmr.0c00017

CONSPECTUS: Organic-inorganic halide perovskite photovoltaics (PVs) - only a decade-old field-have reached impressive power conversion efficiencies (PCEs) and passed industrial stability requirements (IEC 61215:2016 Damp Heat and Humidity Freeze tests), solidifying their status among candidates for next generation PVs. Among the various perovskite PV technologies, all-perovskite tandem solar cells (PTSCs) are frontrunners for commercialization. PTSCs unite a narrow-bandgap (NBG; $E_{\mathrm{g}} \approx$ $1.2 \mathrm{eV}$ ) perovskite back cell with a wide-bandgap (WBG; $E_{\mathrm{g}} \approx$ 1.7-1.9 eV) perovskite front cell. Despite their nascency, PTSCs have achieved certified PCEs of $24.8 \%$ and $24.2 \%$ for small-area $\left(0.049 \mathrm{~cm}^{2}\right)$ and large-area devices $\left(1.041 \mathrm{~cm}^{2}\right)$, respectively. With further advances in materials development, PTSCs are capable of

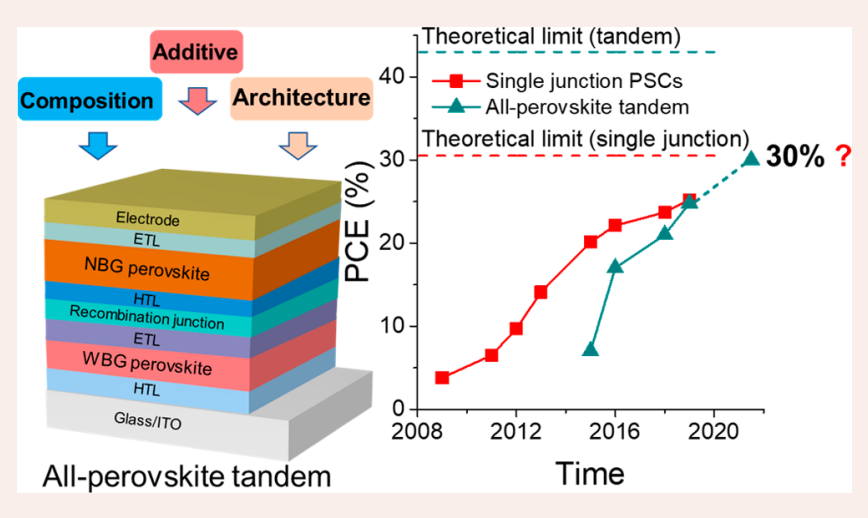
moving beyond the PCE limits of single-junction cells due to reduced thermalization losses and improved utilization of the solar spectrum. By contrast, the PCE of single-junction perovskite devices is already approaching its saturation level, which is already very close to the device's Shockley-Queisser limit for a bandgap of around $1.55 \mathrm{eV}$. The tandem architecture, thus, provides the most viable path forward to further exploiting the potential of perovskite solar cells.

However, PTSC technology faces a set of challenges distinct from those in perovskite single-junction devices because (i) NBG perovskites - typically achieved by $\mathrm{Pb}-\mathrm{Sn}$ alloying-are prone to oxidation $\left(\mathrm{Sn}^{2+}\right.$ to $\left.\mathrm{Sn}^{4+}\right)$, which results in a high density of $\mathrm{Sn}$ vacancies that degrade the optoelectronic performance of NBG perovskite films, (ii) practically complete photon absorption and charge extraction require thick, NBG perovskite films having long carrier diffusion lengths, and (iii) WBG perovskites with high Br/ $(\mathrm{I}+\mathrm{Br})$ ratio experience large voltage losses and inferior light stability due to surface trap states and phase segregation.

In this Account, we discuss how to manage these considerations and maximize the power output in PTSCs via light management. We then review strategies, including composition- and additive-engineering, defect passivation, and matching charge transport layers, for enhancing the carrier diffusion length of NBG perovskite cells and mitigating voltage losses in WBG perovskite cells. We also summarize the advances made in the fabrication of PTSCs on the device level, especially the evolution of tunnel recombination junctions and tandem device architectures. Finally, we highlight further research efforts needed to overcome roadblocks to commercialization (e.g., improving the environmental, thermal, and operating stability of these devices) and offer our perspective on the future development of this rapidly advancing field.

\section{INTRODUCTION}

In the race for the next generation of commercial photovoltaic (PV) technologies, perovskite solar cells (PSCs) benefit from bandgap tunability, defect tolerance, long carrier diffusion length, and compatibility with scalable manufacturing. ${ }^{1-6}$ Over the past decade, the surge in the power conversion efficiency (PCEs), from $3.8 \%$ to $25.2 \%$, of single-junction PSCs has made the highest-PCE cells comparable in performance to silicon counterparts. ${ }^{7,8}$ However, the pace of efficiency growth has considerably slowed down as single-junction perovskite devices approach the single-junction limit. Fortunately, tandem device architectures that combine narrow-bandgap (NBG; $\sim 1.2 \mathrm{eV}$ ) and wide-bandgap (WBG; $1.7-1.9 \mathrm{eV}$ ) light-harvesting layers promise even higher PCEs, potentially exceeding the Shockley-
Queisser (SQ) limit of single-junction devices via reduced thermalization losses and improved utilization of the solar spectrum. $^{9-11}$

Given their tailored bandgaps, halide perovskite semiconductors can supply both narrow- and wide-bandgap absorbers for the assembly of all-perovskite tandem solar cells

Received: July 27, 2020

Revised: September 13, 2020 

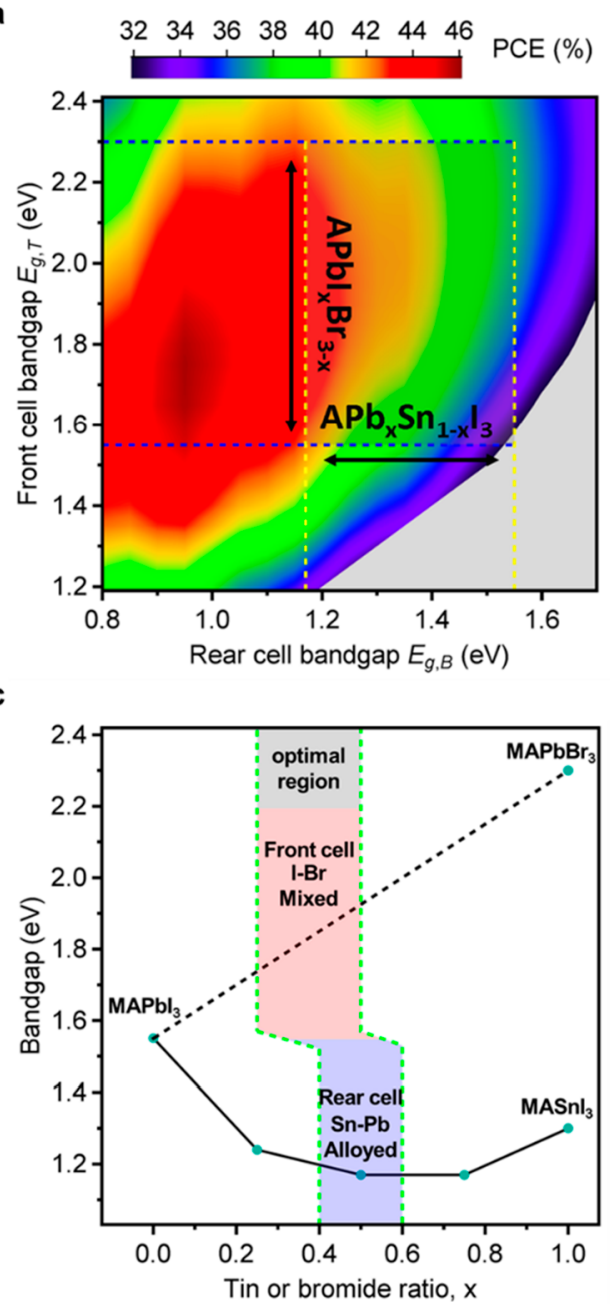

b

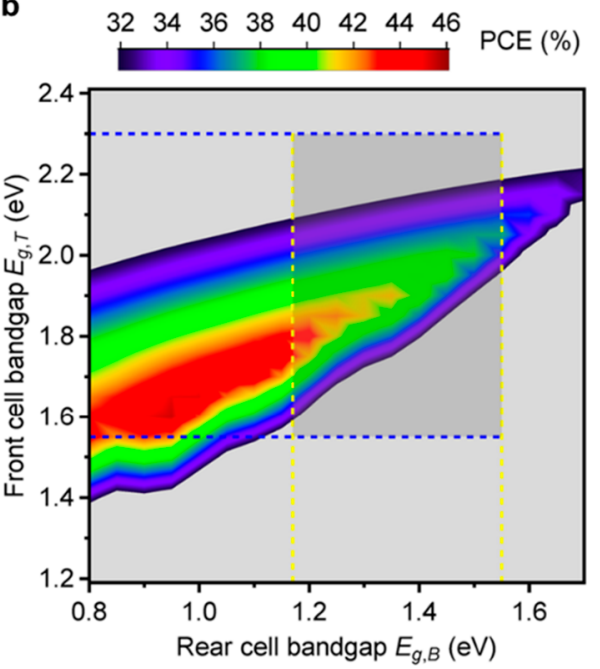

d
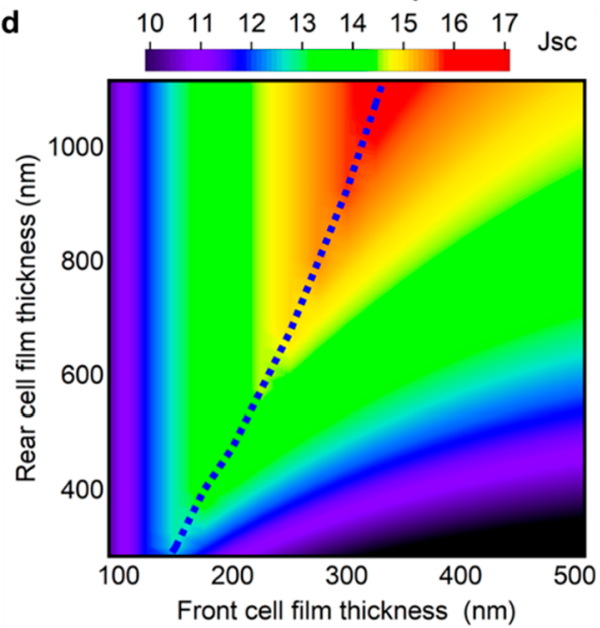

Figure 1. Light management in PTSCs. Theoretical PCE dependence on the bandgaps of the front and rear subcells in 4T (a) and 2T tandem configurations (b). The lines represent the permissible bandgaps of lead iodide perovskites mixed with bromide (front subcell) and tin (rear subcell), forming a rectangle (highlighted) with the potential theoretical PCEs. (c) Bandgap tuning achieved by varying the halide or metal composition. The highlighted region indicates the optimal bandgap ranges for maximizing tandem performance. The data points for plotting the mixed $\mathrm{Sn}-\mathrm{Pb}$ bandgap vs the tin ratio were obtained from ref 20. (d) Simulated minimum $J_{\text {SC }}$ of a 2T PTSC as a function of active layer thickness. The dashed line represents the current-matching condition. The simulation was performed by assuming a device EQE of $90 \%$, and the data pertaining to the active layers absorption coefficient were obtained from ref 21 .

(PTSCs). Their manufacture is expected to be less capitalintensive than is silicon purification and cell fabrication. Recent advances in PTSCs have delivered a certified PCE of $24.8 \%$, and we discuss in here the path to $>30 \%$. $^{12}$

On the way to wider impact, PTSC technology faces a set of challenges distinct from those in perovskite single-junction devices. Lowering the bandgap of the NBG rear cell typically to as low as $1.2 \mathrm{eV}$ relies today on $\mathrm{Pb}-\mathrm{Sn}$ alloying. The $\mathrm{Sn}^{2+}$ ion has the propensity to oxidize to $\mathrm{Sn}^{4+}$, and $\mathrm{Sn}$-containing perovskites adversely react with commonly used hole transport materials (HTMs; e.g., PEDOT:PSS), especially under thermal stress. $^{13-15}$ Consequently, the inclusion of Sn without novel oxidization mitigation strategies hampers both the efficiency and stability of PTSCs. ${ }^{15}$ Other material prerequisites for NBGs also create constraints on PTSCs. For instance, to ensure sufficient absorption of the light filtered by the WBG front cell, a NBG perovskite film thicker than $1 \mu \mathrm{m}$ is needed, which requires that NBG perovskite films support long carrier diffusion lengths to facilitate charge extraction. ${ }^{16,17}$
In the front cell, WBG perovskites also face several challenges. Although the voltage losses of a direct bandgap $1.53 \mathrm{eV}$ perovskite $(\sim 0.35 \mathrm{~V})$ are already lower than those of their indirect bandgap silicon counterparts $(\sim 0.37 \mathrm{~V})$, WBG PSCs still suffer from large voltage losses due to their tendency to form a high density of deep traps. ${ }^{9}$ Moreover, the high bromine content of WBG perovskites leads to the material's tendency to phase segregate under illumination, resulting in inferior light stability. ${ }^{18}$ Therefore, to manifest the full potential of PTSCs, the challenges facing NBG and WBG perovskites need to be addressed with new materials design and processing strategies.

In this Account, we discuss recent advances in PTSC performance, including optical management, enhanced carrier diffusion length of NBG perovskite cells, and suppressed voltage losses in WBG perovskite cells. These factors are elaborated upon with respect to NBG/WBG perovskites and within the context of tandem devices. We highlight approaches for improving the environmental and operational stability of these devices and offer our perspectives on the future development of this growing field. 

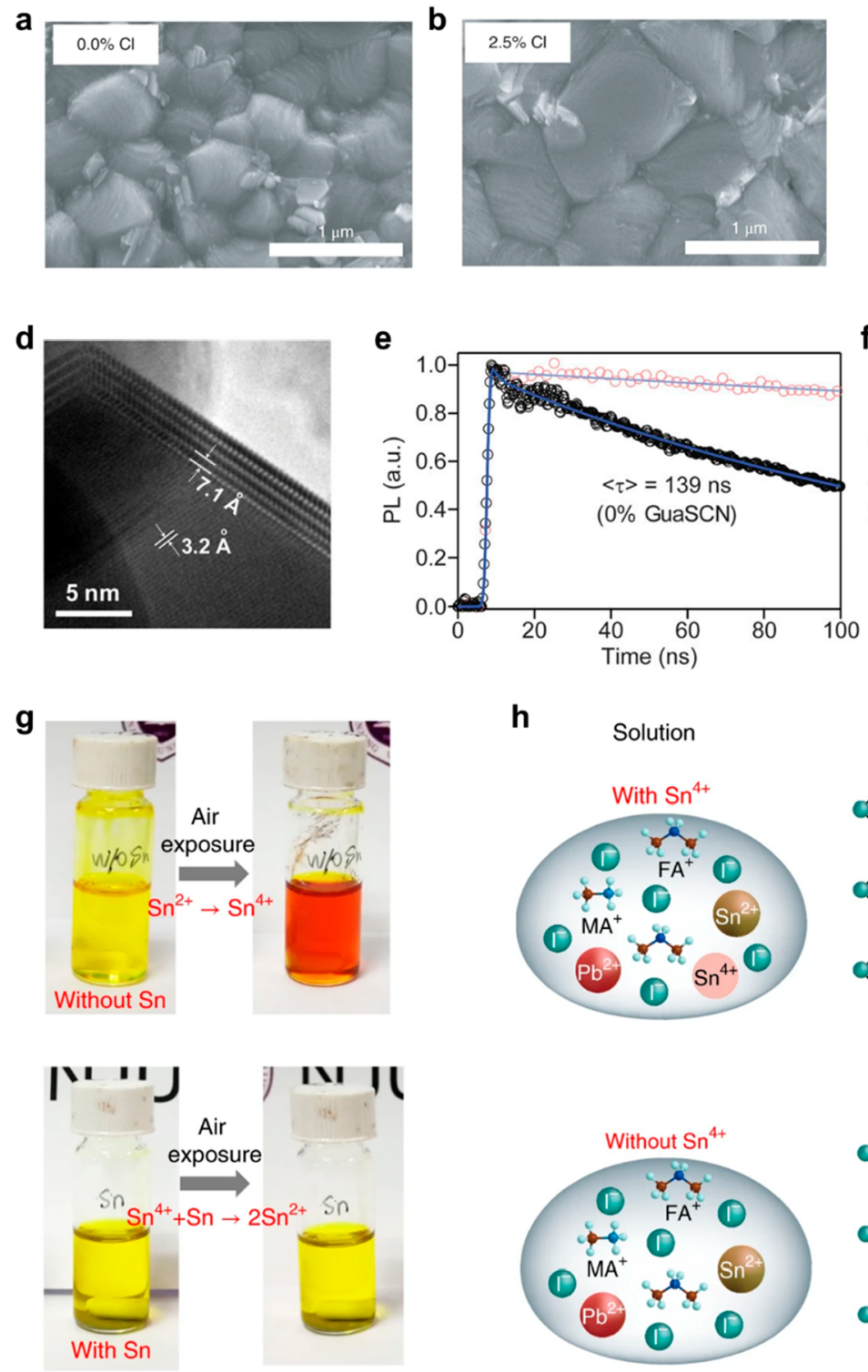
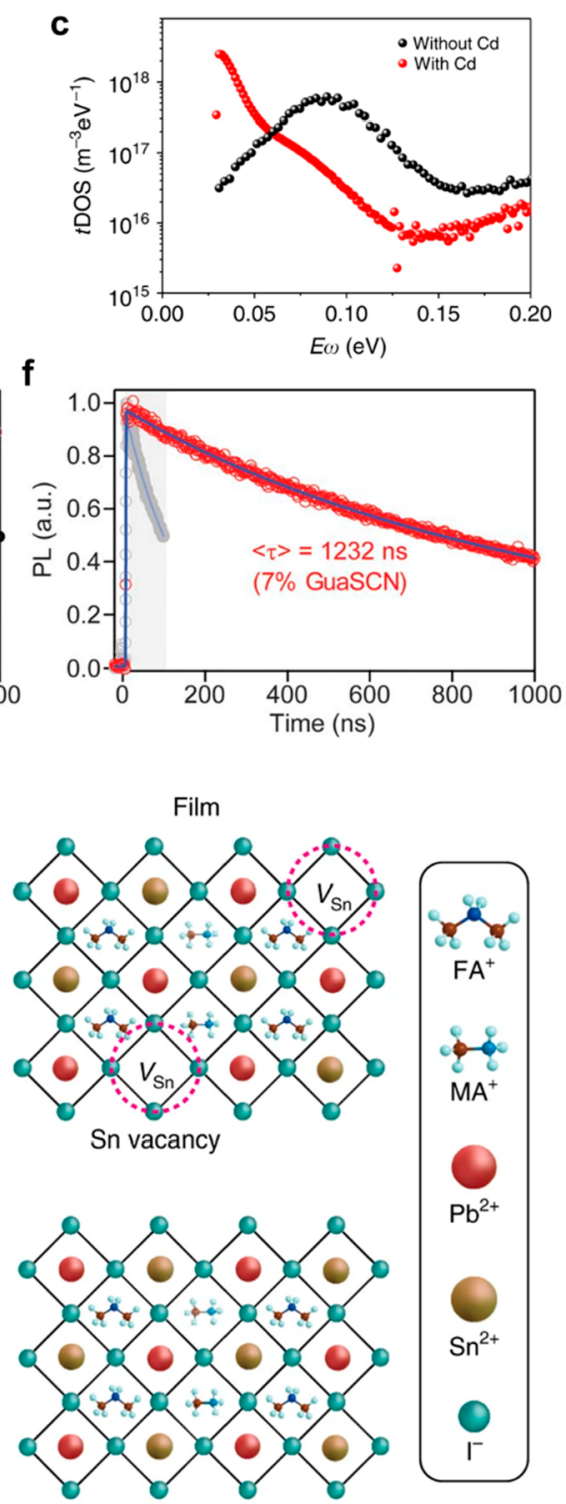

Figure 2. Improvement of NBG film quality and charge carrier diffusion length. (a, b) Scanning electron microscopy (SEM) images of $\mathrm{MA}_{0.4} \mathrm{FA}_{0.6} \mathrm{Sn}_{0.6} \mathrm{~Pb}_{0.4} \mathrm{I}_{3}$ thin films with (a) $0 \%$ and (b) $2.5 \% \mathrm{MACl}$ incorporation. Reproduced with permission from ref 17 . Copyright $2018 \mathrm{Nature}$ Publishing Group. (c) Trap density of states (tDOS) profiles of $\mathrm{Pb}-\mathrm{Sn}$ perovskite solar cells with and without $\mathrm{Cd}^{2+}$. Reproduced with permission from ref 19. Copyright 2019 Nature Publishing Group. (d) HRTEM image of a grain boundary in a $\mathrm{Pb}-$ Sn perovskite films with $7 \% \mathrm{GuaSCN}$ additive. (e, f) Charge carrier lifetimes of $\mathrm{Pb}-\mathrm{Sn}$ perovskite films prepared with (e) $0 \%$ and (f) $7 \%$ GuaSCN. Reproduced with permission from ref 26 . Copyright 2019 American Association for the Advancement of Science. (g) Photographs of precursor solutions when exposed to ambient air without and with Sn powder and $(\mathrm{h})$ corresponding illustration of vacancy formation and suppression in the $\mathrm{Pb}-\mathrm{Sn}$ perovskite lattice. Reproduced with permission from ref 29. Copyright 2019 Nature Publishing Group.

\section{LIGHT MANAGEMENT}

Depending on the degree of electrical connectivity, tandem solar cells vary in design and are mainly classified as either 4-terminal (4T) or 2-terminal (2T or monolithic) devices. Figure $1 \mathrm{a}, \mathrm{b}$ shows the theoretical PCE limit of both the 4T and 2T dualjunction configurations as a function of the front- and rear-cell bandgaps. The first thing to note is the greater front cell bandgap selection room for the $4 \mathrm{~T}$ design compared with that of the $2 \mathrm{~T}$ one. The constraint on materials choice in the $2 \mathrm{~T}$ design stems from the requirement of photocurrent matching between the inseries connected subcells. This restriction limits the front cell's bandgap to $1.75-1.85 \mathrm{eV}$ to attain the most efficient device. Moreover, the $2 \mathrm{~T}$ configuration must accommodate spectral adjustments to maintain the current matching condition. In either configuration, alloying with tin to lower the bandgap is crucial for performance. Thus, the advancement of $\mathrm{Pb}-\mathrm{Sn}$ based NBG rear cells is key to achieving efficient $2 \mathrm{~T}$ and $4 \mathrm{~T}$ PTSCs, despite the instability of $\mathrm{Sn}^{2+}$.

Although the $2 \mathrm{~T}$ configuration presents itself with distinctive challenges, its monolithic integration offers lower anticipated production costs and lower performance losses. Omitting the transparent electrode of the 4T's rear cell reduces not only cost but also the accompanying parasitic reflection and absorption from the extra electrode, substrate, and interfaces. This modification, in turn, allows tandem devices to reach higher overall PCEs. 
Controlling the bandgap of the active layer is a prerequisite to attaining the best tandem device performance. Fortunately, the bandgap of metal halide perovskites can be easily tuned via composition engineering. Figure 1c shows the common method for steering away from the standard bandgap of the most typical perovskite, $\mathrm{MAPbI}_{3}$. Mixing with bromide results in a nearly linear increase in the bandgap from 1.5 to $2.3 \mathrm{eV}$, whereas alloying with tin $\left(\mathrm{Sn}^{2+}\right)$ lowers the bandgap to $\sim 1.2 \mathrm{eV}$ in a nonlinear fashion with a bowing effect. The lowest bandgap can be achieved with an atomic ratio of $\sim 60 \% \mathrm{Sn}^{2+}$, although a lower percentage of $\mathrm{Sn}^{2+}$ is preferred to minimize the instabilities and poor film quality caused by the introduction of $\mathrm{Sn}^{2+}$.

The tunnel recombination junction (TRJ), in which electrons and holes recombine in 2T PTSCs, should exhibit both excellent transparency and conductivity, between which a trade-off exists. The most common TRJ, magnetron-sputtered ITO, displays such favorable properties; however, the material is costly and brittle and might damage the underlying perovskite layer during the sputtering process, in which case a protecting buffer layer is needed prior to deposition. The unique properties of perovskite materials impose different requirements on the TRJ in PTSCs. Thus, research in this area is greatly needed for the development of efficient $2 \mathrm{~T}$ devices (discussed in more detail in the section All-Perovskite Tandems).

To match the photocurrent of each sub cell, the thickness of the active layer is tuned to adjust corresponding absorption. Figure $1 \mathrm{~d}$ shows a simulation of the $J_{\mathrm{SC}}$ of a $2 \mathrm{~T}$ PTSC as a function of the thickness of the absorber layers: a $1.8 \mathrm{eV}$ WBG front subcell and a $1.2 \mathrm{eV} \mathrm{NBG}$ rear subcell (assuming an overall external quantum efficiency (EQE) of 90\%). The dashed line indicates where the current is matched, with the region to the right generating a higher front-cell photocurrent and that to the left a higher rear-cell photocurrent. As the figure indicates, the overall $J_{\mathrm{SC}}$ is limited by the NBG rear cell, which requires a thickness of $\sim 1000 \mathrm{~nm}$ to approach the maximum $J_{\mathrm{SC}}$. This limitation stems from the inferior absorption coefficient of the $\mathrm{Pb}-\mathrm{Sn}$ NBG perovskite layer in the near-infrared region (750$1000 \mathrm{~nm}){ }^{19}$

\section{ENHANCING CARRIER DIFFUSION LENGTH IN NARROW-BANDGAP REAR CELL}

The PCEs of PTSCs were initially hampered by the NBG rear cell's poor absorption coefficient in the near-infrared region. Utilizing thicker films to effectively absorb the incoming light resulted in thicknesses exceeding the carrier diffusion length and subsequent losses in performance. These problems mainly stem from the tendency of $\mathrm{Sn}^{2+}$ to oxidize to $\mathrm{Sn}^{4+}$, generating a high density of defects with poor optoelectronic qualities.

To mitigate these unfavorable effects, Kumar et al. added $\mathrm{SnF}_{2}$ as a reducing agent and observed a significant improvement in the PV parameters of $\mathrm{CsSnI}_{3}$ solar cells. ${ }^{22}$ Since then, $\mathrm{SnF}_{2}$ has proven to be an indispensable additive in the fabrication of efficient NBG rear cells. Efforts in advancing NBG subcells have mainly focused on improving the quality of the NBG film and improving its charge carrier diffusion length.

Pinhole-free films are essential for perovskite devices to avoid shunting and losses in performance. Considering their poor film formation, Eperon et al. developed a deposition strategy in which a spin-coated perovskite-solvent-complex film is dipped into an antisolvent bath for crystallization, instead of adopting the standard technique of antisolvent dripping used to fabricate lead halide films. ${ }^{23}$ This strategy, called precursor-phase antisolvent immersion deposition (PAI), allowed for smoother and more uniform tin-containing films to be deposited, resulting in a $\mathrm{FA}_{0.75} \mathrm{Cs}_{0.25} \mathrm{Sn}_{0.5} \mathrm{~Pb}_{0.5} \mathrm{I}_{3} \mathrm{NBG}$ single-junction PCE of $14.1 \%$ and a $2 \mathrm{~T}$ PTSC of $16.8 \%$.

Larger grains tend to show lower defect densities and higher crystallinity, which boost the diffusion length and device performance. Zhao et al. increased the concentration of the precursor solution such that the thickness of the active layer $\left(\mathrm{MA}_{0.4} \mathrm{FA}_{0.6} \mathrm{Sn}_{0.6} \mathrm{~Pb}_{0.4} \mathrm{I}_{3}\right)$ was altered from 400 to $620 \mathrm{~nm}$, which led to the formation of larger grains with higher crystallinity and longer charge carrier lifetimes. ${ }^{16}$ As a result, an EQE exceeding $70 \%$ in the infrared (IR) region and a $J_{S C}$ value of $28.3 \mathrm{~mA} \mathrm{~cm}^{-2}$ were achieved. In a follow-up study by the same group, $2.5 \%$ of the iodide was replaced with chloride $(\mathrm{Cl})$, which was found to further enhance the crystallinity and grain size (Figure 2a,b), allowing for an $18.1 \%$-efficient device to be constructed from a $750 \mathrm{~nm}$ thick absorber with minimal losses in the $V_{\mathrm{OC}}$ and FF. Coupled with a $1.75 \mathrm{eV}$ wide-bandgap front cell, a $21 \%$-efficient $2 \mathrm{~T}$ device was fabricated. ${ }^{17}$

Likewise, Leijtens et al. prepared thicker films $(\sim 700 \mathrm{~nm})$ of $\mathrm{FA}_{0.75} \mathrm{Cs}_{0.25} \mathrm{Sn}_{0.5} \mathrm{~Pb}_{0.5} \mathrm{I}_{3}$ by varying the concentration and observed larger grains with better lifetimes and EQEs exceeding $80 \%$ in the IR region. ${ }^{24}$ In addition, a $\mathrm{MACl}$ vapor posttreatment was applied to the PAI-deposited films to heal cracks and further grow the grains, which increased the $V_{\mathrm{OC}}, \mathrm{FF}$, and stability, yielding a stabilized PCE of $15.6 \%$.

Protecting the grain boundaries and surfaces with a defectpassivating layer has been key for PSCs and is arguably more important for Sn-containing oxygen-sensitive films. ${ }^{25}$ Tong et al. found that guanidinium thiocyanate (GuaSCN) additives had a dual effect of enlarging grains and reducing $\mathrm{Sn}$ vacancies by forming a two-dimensional (2D) structure at the grain boundaries and surface of NBG $\mathrm{Pb}-\mathrm{Sn}$ perovskite films (Figure $2 \mathrm{~d}) .^{26}$ The construction of a $2 \mathrm{D}-3 \mathrm{D}$ heterostructure is an effective way to passivate a defective surface, prevent the diffusion of $\mathrm{Sn}$ toward the grain surface, limit oxygen from diffusing into grains, and improve film stability. Overall, the reduced defect density led to an increase in the carrier lifetime to more than $1 \mu \mathrm{s}$ and an increase in the diffusion length from 500 $\mathrm{nm}$ to $2.5 \mu \mathrm{m}$ (Figure $2 \mathrm{e}, \mathrm{f}$ ); these changes allowed for a $1000 \mathrm{~nm}$ thick active layer to be incorporated, resulting in a $J_{\mathrm{SC}}$ of $30.4 \mathrm{~mA}$ $\mathrm{cm}^{-2}$ and a champion PCE of $20.5 \%$. Combined with a WBG front cell, 25\%-efficient $4 \mathrm{~T}$ and $23 \%$-efficient $2 \mathrm{~T}$ tandem devices were achieved. Similarly, Wei et al. anchored the NBG film grains with phenethylammonium (PEA) ligands to passivate the defects and enhance the device stability. ${ }^{27}$ As a result, a 200 -fold enhancement in the device operating lifetime and a jump from $17.9 \%$ to $19.4 \%$ PCE ( $18.95 \%$ certified) were observed.

Although $\mathrm{SnF}_{2}$ has been a key ingredient in limiting the oxidation of $\mathrm{Sn}^{2+}$, it does not sufficiently prevent it, as demonstrated by $\mathrm{Gu}$ et al. ${ }^{28}$ The researchers coupled $\mathrm{SnF}_{2}$ with another reducing agent, elemental $\mathrm{Sn}$, and observed the red precursor solution of $\mathrm{FASnI}_{3}$ reverted to yellow in the presence of oxygen, indicating effective suppression of $\mathrm{Sn}^{4+}$ via a comproportionation reaction (Figure $2 \mathrm{~g}, \mathrm{~h}$ ). ${ }^{28,29}$ Because it was insoluble in the solution, the metallic tin powder was filtered out before spin-coating the films. Lin et al. applied this strategy to $\mathrm{Pb}-\mathrm{Sn}$ films and observed an increase in the films' carrier diffusion length to $3 \mu \mathrm{m}$, allowing for the device $J_{\mathrm{SC}}$ to exceed 32 $\mathrm{mA} \mathrm{cm}{ }^{-2}$. ${ }^{29}$ PCEs of $21.1 \%$ and a certified $24.8 \%$ were achieved for the small area single-junction NBG and 2T PTSCs, respectively, and most recently, a PCE of $24.2 \%$ for $1 \mathrm{~cm}^{2}$ large area 2T PTSCs was reported by same group. ${ }^{30}$ In another study, Nakamura et al. reacted a dihydropyrazine derivative with 

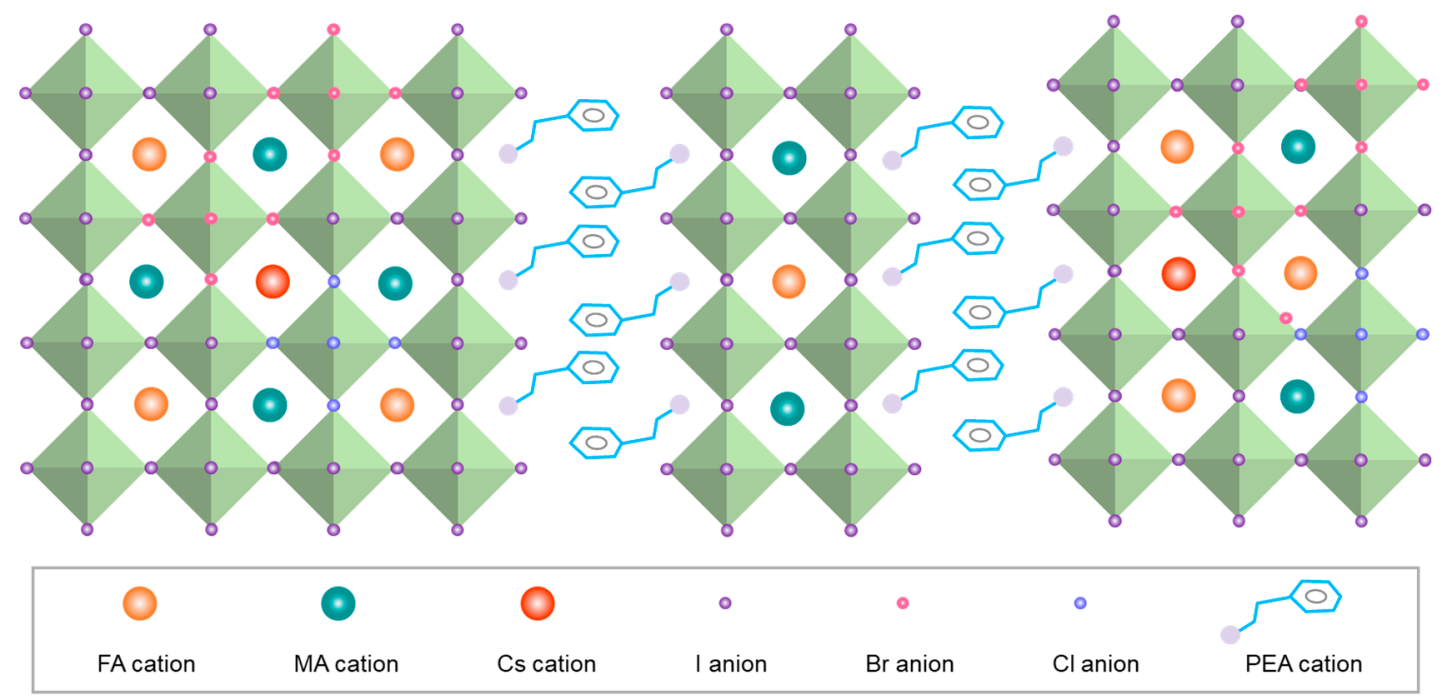

b

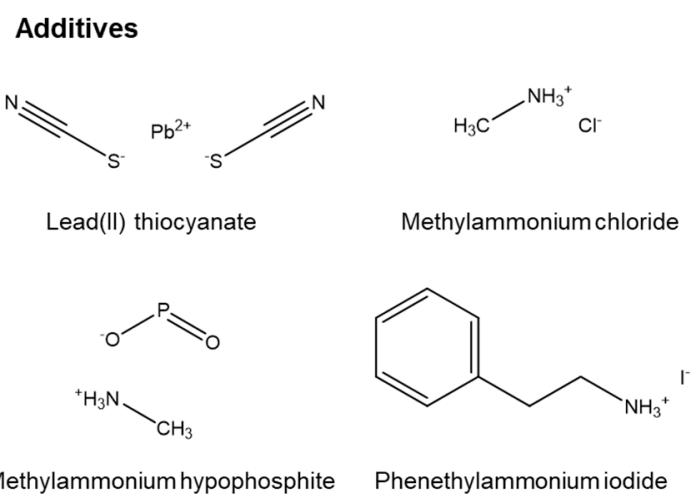

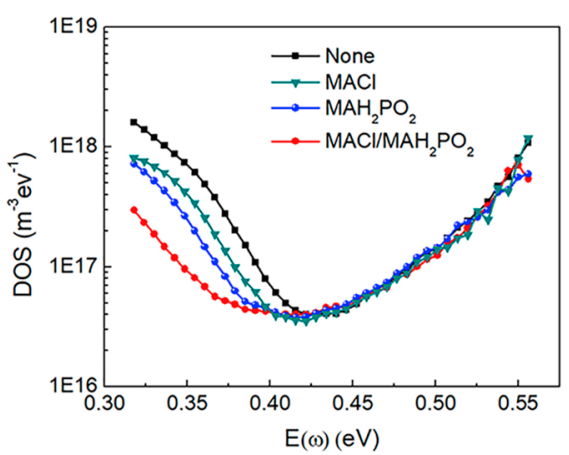

d

Surface passivation and reduce ETL disorder
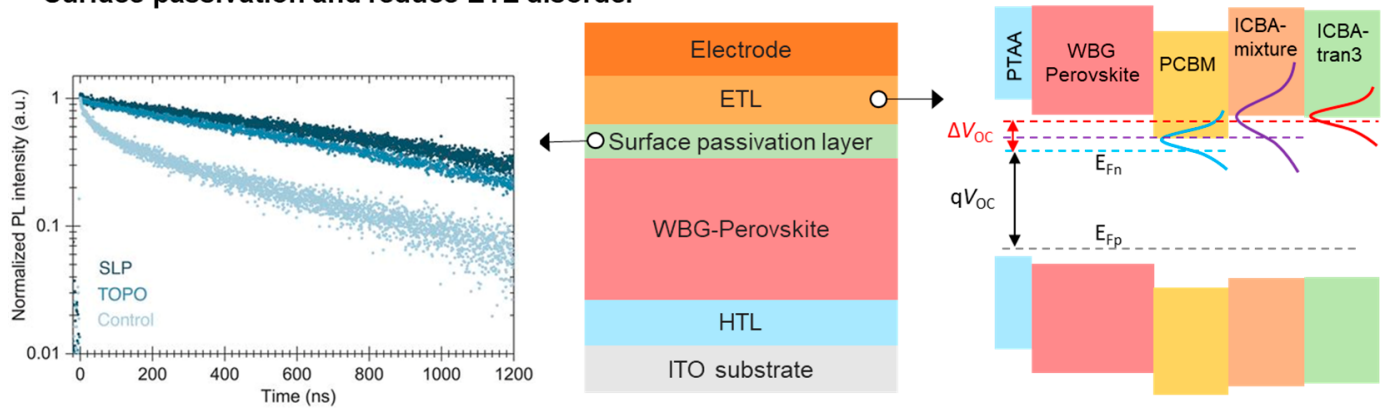

Figure 3. Voltage loss mitigation in the WBG perovskite front cell. (a) Illustration of composition engineering of WBG PSCs. (b) Chemical structures of widely used additives in processing of WBG PSCs. (c) Trap density of states of WBG PSCs with different additives. Reproduced with permission from ref 50. Copyright 2019 Cell Press. (d) Surface passivation (left panel) and matching charge extraction contact (right panel) for WBG PSCs. Reproduced with permission from ref 54. Copyright 2020 American Association for the Advancement of Science. Reproduced with permission from ref 56. Copyright 2017 Wiley.

the $\mathrm{SnF}_{2}$ precursor present in the solution to form $\mathrm{Sn}$ nanoparticles that further reduce $\mathrm{Sn}^{4+}$ to $\mathrm{Sn}^{2+}$. ${ }^{31}$ They used this strategy to fabricate lead-free solar cells of $\mathrm{FA}_{0.75} \mathrm{MA}_{0.25} \mathrm{SnI}_{3}$ with a PCE of $11.5 \%$ and $V_{\mathrm{OC}}$ of $0.76 \mathrm{~V}$.

Another interesting strategy to counteract the presence of $\mathrm{Sn}$ vacancies is by filling them with a more stable metal cation. Because the oxidation of $\mathrm{Sn}^{2+}$ induces self-doping, Yang et al. proposed that $\mathrm{Cd}^{2+}$ can fill these vacancies and dedope $\mathrm{Sn}$ containing perovskites. ${ }^{19}$ The authors further explored the type of carriers inhibiting the PCE of NBG devices and found that the electron diffusion length was a limiting factor. To address that limitation, perovskite films were doped with a trace amount of $\mathrm{Cd}^{2+}(<0.1 \mathrm{~mol} \%)$, which reduced trap state density and enhanced the diffusion length of electrons to $2.7 \mu \mathrm{m}$ (Figure $2 \mathrm{c}$ ), enabling a $1000 \mathrm{~nm}$ active layer to be incorporated efficiently with a $J_{\mathrm{SC}}$ exceeding $30 \mathrm{~mA} \mathrm{~cm} \mathrm{~cm}^{-2}$.

Pure Sn-based absorbers with bandgaps of around $1.3 \mathrm{eV}$ have been used to fabricate lead-free NBG PSCs. Devices based on $3 \mathrm{D} \mathrm{FASnI}_{3}$ have achieved PCEs over $12 \%,{ }^{32-34}$ and those based on inorganic compositions (such as $\mathrm{CsSn}_{0.5} \mathrm{Ge}_{0.5} \mathrm{I}_{3}$ and $\mathrm{Cs}_{2} \mathrm{SnI}_{6}$ ) 
have achieved PCEs over 7\%. ${ }^{13}$ The $\mathrm{FASnI}_{3}$-based devices also showed good operational stability (23\% efficiency loss after 500 $\mathrm{h}$ tracking in $\mathrm{N}_{2}$ under 1-sun illumination), which was realized by incorporation of a bulky divalent organic cation (4(aminomethyl)piperidinium (4AMP)). ${ }^{35}$ The operational stability of encapsulated $\mathrm{Sn}$-based devices in ambient air is yet to be uncovered.

\section{VOLTAGE LOSS MITIGATION IN WIDE-BANDGAP FRONT CELLS}

WBG PSCs still suffer from large $V_{\text {OC }}$ losses, which limit overall device performance. These voltage losses mainly stem from the high trap density of WBG PSCs. ${ }^{36,37}$ Numerous attempts have been made by the community to tackle this challenge. ${ }^{38,39}$ PTSCs require a larger bandgap $(1.75-1.8 \mathrm{eV})$ front cell than that of silicon-perovskite tandems $(1.65-1.7 \mathrm{eV})$, and this makes phase separation easier for WBG perovskites of PTSCs with a larger ratio of bromine. However, they share some common rules of defect chemistry and ways to suppress voltage loss; therefore, in this section, we summarized the efforts made to reduce voltage losses for WBG PSCs with a bandgap ranging from $\sim 1.65$ to $1.8 \mathrm{eV}$. Among these attempts, composition engineering has attracted intensive research efforts, as summarized in Figure 3a. Tan et al. reported a cation engineering strategy to increase the defect tolerance of WBG perovskites, in which dipolar methylammonium (MA) cations were introduced into widely used WBG perovskite compounds with mixed cations of formamidinium (FA) and cesium (Cs). ${ }^{36}$ Specifically, dipolar MA cation reorientation heals deep traps, leading to $19.1 \%$-efficient $1.74 \mathrm{eVWBG}$ PSCs with a high $V_{\mathrm{OC}}$ of $1.25 \mathrm{~V}$. Tuning the $\mathrm{Br} /(\mathrm{I}+\mathrm{Br})$ ratio in mixed halide perovskite is a general approach for achieving WBG perovskites with an ideal bandgap of $\sim 1.7 \mathrm{eV}$. Deviating from this approach, $\mathrm{Xu}$ et al. demonstrated a distinct chlorine $(\mathrm{Cl})$ alloying strategy that efficiently increased the bandgap of $\mathrm{I}-\mathrm{Br}$ mixed perovskites toward a desired value $(1.67 \mathrm{eV}) .{ }^{40}$ Triple-halide alloys $(\mathrm{Cl}, \mathrm{Br}$, I) exhibited an enhancement in both the charge-carrier mobility and lifetime by a factor of nearly 2 compared with those of the best $1.67 \mathrm{eV}$ controls, potentially arising from the reduction in the halogen vacancy defect density via elemental compensation with the smaller $\mathrm{Cl}$ ions. Alloying with $\mathrm{Cl}$ led to a champion triple-halide device with a PCE of $20.42 \%$ and $V_{\text {OC }}$ of $1.217 \mathrm{~V}$. The function of defect passivation by $\mathrm{Cl}$ ions has also been observed in other studies, such as when using ligand-capped $\mathrm{CsPBrCl}_{2}$ QDs in the antisolvent processing of $\mathrm{MAPbI}_{3}$ films. ${ }^{41}$

Figure $3 \mathrm{~b}$ summarizes the additives used in processing WBG PSCs for PTSCs. $\mathrm{Pb}(\mathrm{SCN})_{2}$ has been demonstrated to increase the grain size of WBG films. ${ }^{42,43}$ Bulky organic ammonium additives have been used to form $2 \mathrm{D}-3 \mathrm{D}$ heterostructures, which act as grain boundary passivation agents. ${ }^{44} \mathrm{Kim}$ et al. explored the synergistic functions triggered by introducing two complementary additives-phenethylammonium iodide (PEAI) and $\mathrm{Pb}(\mathrm{SCN})_{2}$-into a $\left(\mathrm{FA}_{0.65} \mathrm{MA}_{0.20} \mathrm{Cs}_{0.15}\right) \mathrm{Pb}$ $\left(\mathrm{I}_{0.8} \mathrm{Br}_{0.2}\right)_{3}$ precursor to construct $2 \mathrm{D}-3 \mathrm{D}$ mixed $\mathrm{WBG}(1.68$ $\mathrm{eV})$ perovskites. However, the independent use of large organic ammonium and $\mathrm{Pb}(\mathrm{SCN})_{2}$ additives gives rise to drawbacks such as more grain boundaries and excess $\mathrm{PbI}_{2}$, respectively. The collective effects of $\mathrm{PEA}^{+}$and $\mathrm{SCN}^{-}$additives have been observed to remarkably improve the structural and optoelectronic properties of WBG perovskite films. ${ }^{45}$ Anion engineering based on $\mathrm{PEA}^{+}$and $\mathrm{SCN}^{-}$additives (mixed PEAI and PEASCN additives with optimized ratio) has also been developed, which has delivered a champion WBG PSC with a PCE of $20.7 \%$ benefiting from the positive roles of both PEA molecules and the $\mathrm{PbI}_{2}$-based $2 \mathrm{D}$ phase at the grain boundaries. ${ }^{46}$ By further tailoring the spacers in 2D-3D heterostructures to improve charge transport, WBG PSCs with PCEs over $21 \%$ have been achieved. ${ }^{47}$ Chen et al. revealed that more conductive and defective grain boundaries of WBG films fundamentally limit the $V_{\text {OC }}$ of WBG PSCs, and the bulky organic ammonium additives created an ion diffusion barrier and reduced the accumulation of detrimental ionic defects at grain boundaries. ${ }^{48}$ Doherty et al. observed the compositional inhomogeneity of $\mathrm{Br}-\mathrm{I}$ mixedhalide perovskite grains with more trap clusters appearing at the interfaces between inhomogeneous grains and homogeneous surrounding material. ${ }^{49}$

Another pair of additives- $\mathrm{MACl}$ and $\mathrm{MAH}_{2} \mathrm{PO}_{2}$ - was reported by Chen et al. $\mathrm{MACl}$ and $\mathrm{MAH}_{2} \mathrm{PO}_{2}$ additives help enhance grain size and grain boundary passivation, respectively. ${ }^{50}$ WBG perovskite films with a long carrier lifetime (291 ns) have been reported, arising from the effects of increasing the grain size and reducing the shallow trap density (Figure 3c).

In addition to composition and additive engineering, surface passivation is paramount to achieving high-performance WBG PSCs, as the film surfaces have been shown to exhibit higher charge trap densities than those of the film bulk (including grain boundaries). ${ }^{51,52}$ Our recent study revealed that low-temperature-grown thin $\mathrm{MAPbI}_{3}$ single crystals exhibited improved surface electronic properties because of suppressed loss of MA cations; this finding indicates that typical high-temperature annealing may result in a high density of vacancies at the surface of perovskite crystals or films and that surface passivation is a prerequisite for pursuing high-efficiency perovskite devices. ${ }^{53}$ Hou et al. illustrated a thiol-based self-limiting passivation (SLP) treatment involving the exposure of WBG films to a homogeneous atmosphere of 1-butanethiol. ${ }^{54}$ Vapor-phase small thiol molecules provided high diffusivity and passivated the top surface of the WBG perovskite films. After the treatment, the time-resolved photoluminescence (TRPL) lifetime increased from 570 to $900 \mathrm{~ns}, \sim 15 \%$ higher than that of films exposed to trioctylphosphine oxide (TOPO) and $\sim 60 \%$ higher than that of control samples (Figure 3d). Surface-anchoring alkylamine ligands (AALs), as grain and interface modifiers, have been demonstrated as an effective way to suppress voltage loss of PSCs. These ligands promote a (100) orientation and a reduction in interface carrier recombination, resulting in remarkably reduced $V_{\mathrm{OC}}$ losses and a certified PCE of $22.3 \%$ for inverted PSCs. ${ }^{55}$ To address both the bulk and surface defects of perovskite films, a ligand-capped $\mathrm{CsPbBCl}_{2} \mathrm{QD}$ dispersion was used as an antisolvent when processing $\mathrm{MAPbI}_{3}$ films to deliver both bulk doping elements and surface passivation agents. The elements from the QDs were uniformly distributed across the thickness of the $\mathrm{MAPbI}_{3}$ films, and the ligands self-assembled on the surface of $\mathrm{MAPbI}_{3}$ films, thus simultaneously realizing bulk and surface passivation. ${ }^{41}$

Lin et al. reported that the mismatched energy levels of charge transport layers also give rise to the large $V_{\mathrm{OC}}$ deficit of WBG PSCs. Compared with the commonly used [6]-phenyl- $\mathrm{C}_{61^{-}}$ butyric acid methyl ester (PCBM), the electron transport layer (ETL) indene- $\mathrm{C}_{60}$ bisadduct (ICBA) has a shallower lowest unoccupied molecular orbital (LUMO) level, yielding a larger $V_{\mathrm{OC}}$ in WBG PSCs. However, the energy disorder of ICBA must be further reduced to improve the $V_{\mathrm{OC}}$. Isolating the isomer ICBA-tran 3 from the ICBA mixture and using it instead is an effective way to reduce the energy disorder of ICBA (Figure 


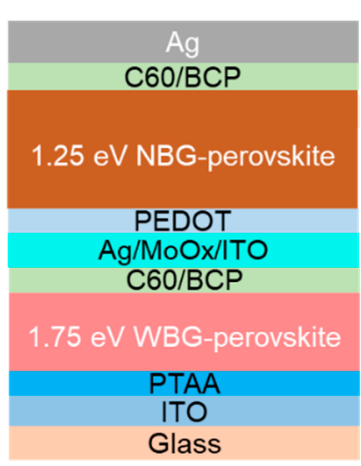

d

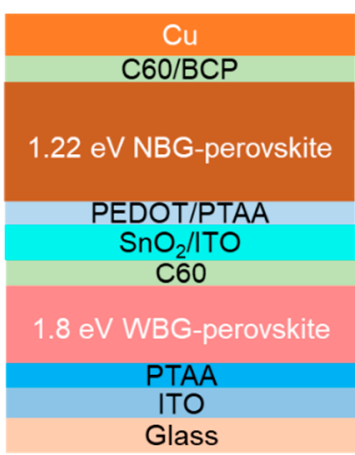

g

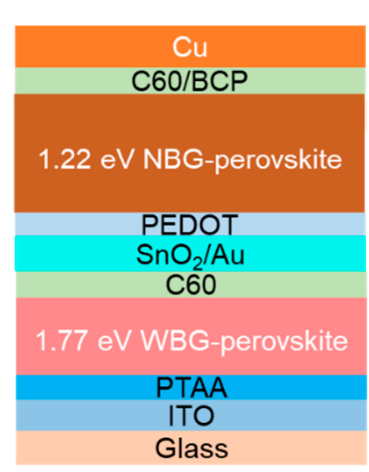

j

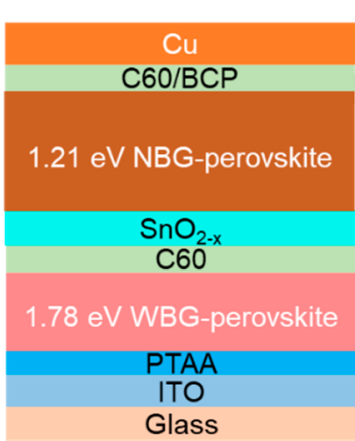

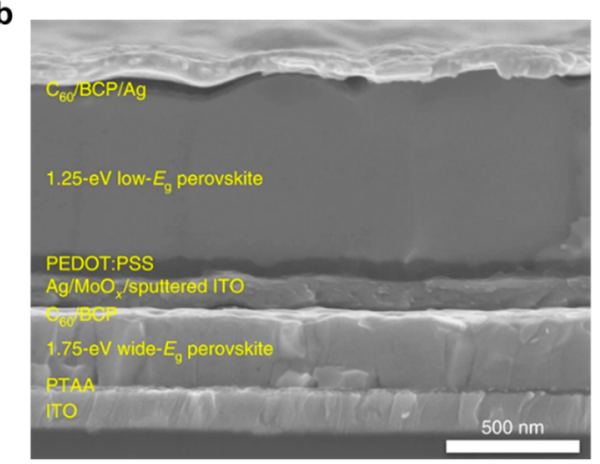
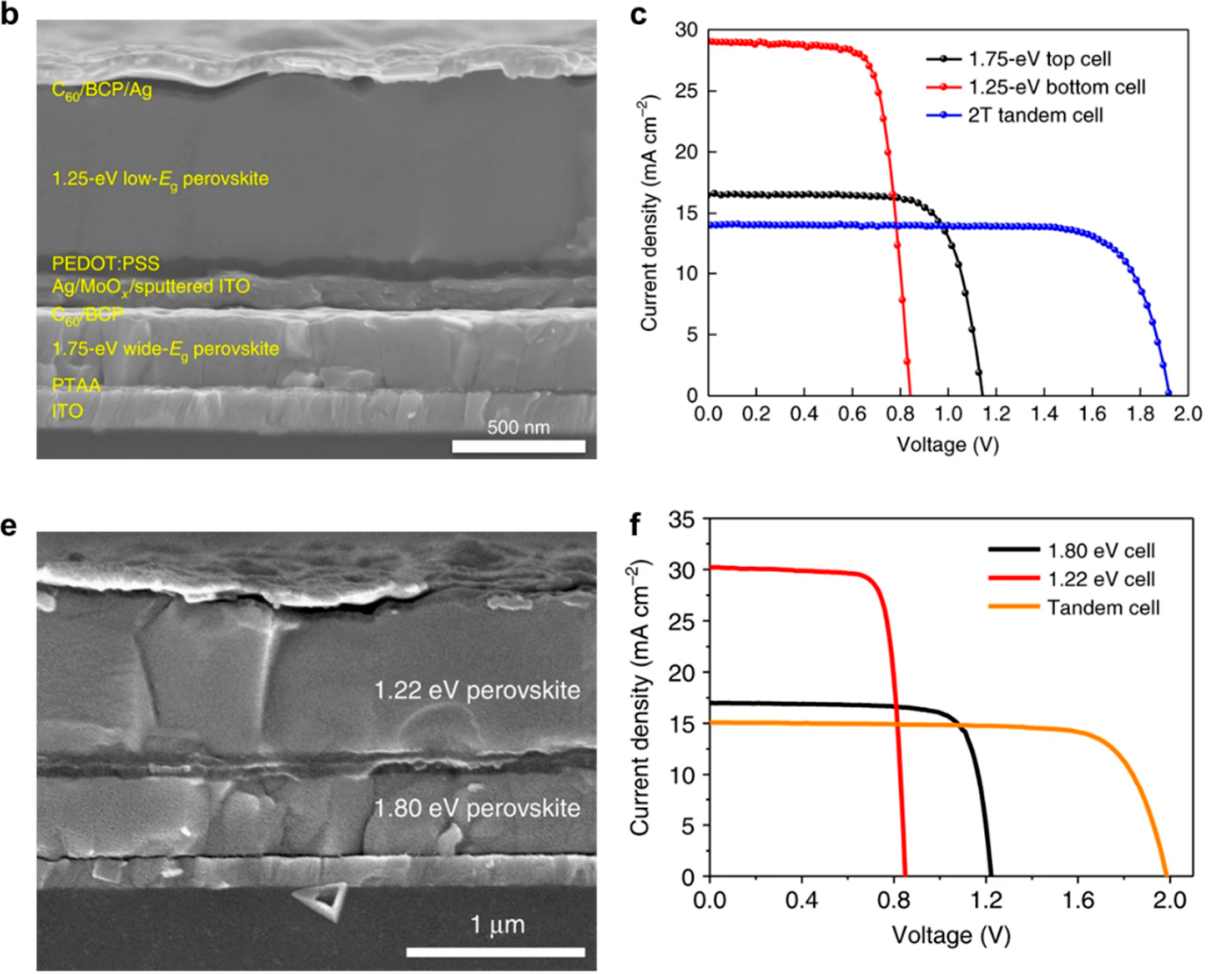

h
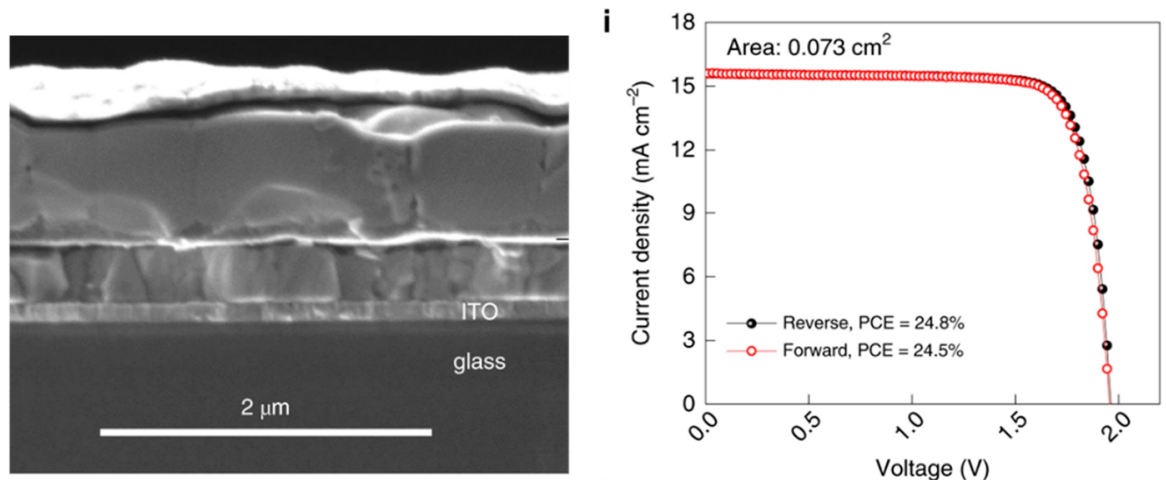

$\mathbf{k}$

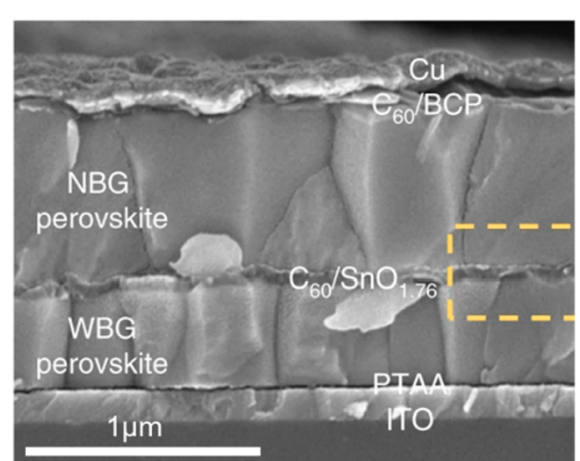

'

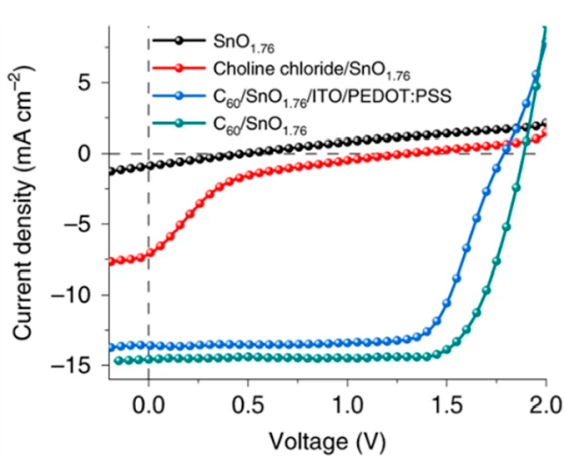

Figure 4. Evolution of PTSC architecture. Schematic illustration of PTSCs using Ag/ $\mathrm{MoO}_{x} / \mathrm{ITO}$ as the TRJ (a) and the corresponding device crosssectional SEM (b) and $J-V$ curves (c). Reproduced with permission from ref 17 . Copyright 2018 Nature Publishing Group. Schematic illustration of PTSCs using $\mathrm{SnO}_{2} /$ ITO as the TRJ (d) and the corresponding device cross-sectional SEM (e) and $J-V$ curves (f). Reproduced with permission from ref 19. Copyright 2019 Nature Publishing Group. Schematic illustration of PTSCs using $\mathrm{SnO}_{2} / \mathrm{Au}$ as the TRJ (g) and the corresponding device crosssectional SEM (h) and $J-V$ curves (i). Reproduced with permission from ref 29. Copyright 2019 Nature Publishing Group. Schematic illustration of PTSCs using $\mathrm{C}_{60} / \mathrm{SnO}_{1.76}$ as the interconnection layer between WBG and NBG cells (j) and the corresponding device cross-sectional SEM (k) and J$V$ curves (1). Reproduced with permission from ref 62. Copyright 2020 Nature Publishing Group.

3d). ${ }^{56}$ In this manner, the $V_{\text {OC }}$ of WBG PSCs with ICBA-tran3 was improved by $60 \mathrm{mV}$. Similarly, Khadka et al. enhanced the crystallinity (i.e., reduced the energy disorder) of fullerene derivatives by using alkyl-chain-substituted fullerene derivatives, 

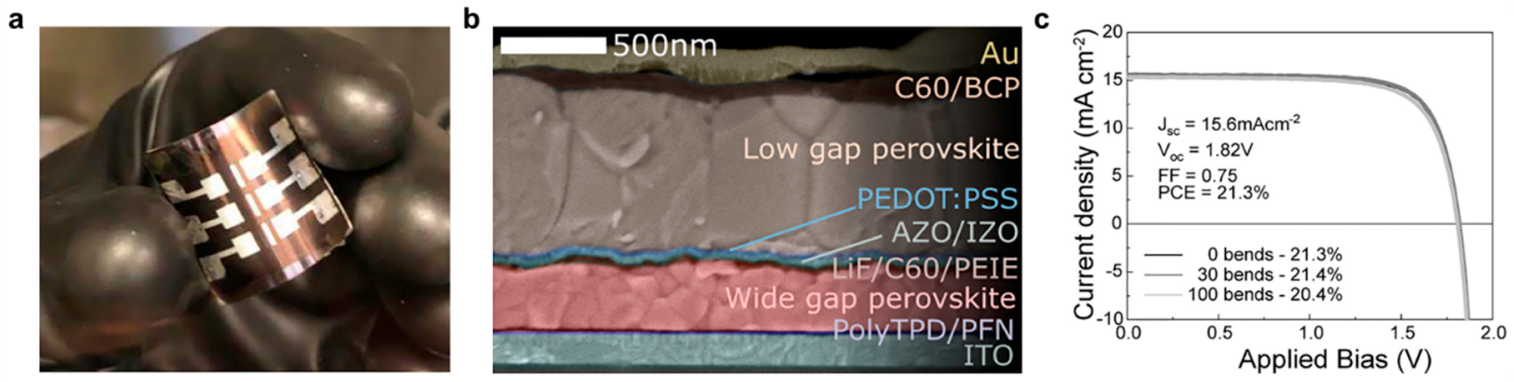

Figure 5. Flexible PTSCs. (a) Photograph of a flexible tandem device. (b) Cross-sectional SEM image of PTSCs. (c) $J-V$ curves for flexible PTSCs. Reproduced with permission from ref 63. Copyright 2019 Cell Press.

namely, $\mathrm{C}_{60}$-fused $\mathrm{N}$-methylpyrrolidine-meta-dodecyl phenyl $\left(\mathrm{C}_{60} \mathrm{MC}_{12}\right) .{ }^{57}$ The reduction in the energy disorder of the ETLs led to a high $V_{\mathrm{OC}}$ of $1.24 \mathrm{~V}$, an increase of $70 \mathrm{mV}$, for $1.71 \mathrm{eV}$ WBG PSCs.

The above-mentioned WBG PSCs are based on mixed-halide $(\mathrm{Br}-\mathrm{I})$ lead perovskites. Lead-free perovskites are also promising for WBG PSCs. Sn-based perovskites with incorporation of large organic cations, such as ethylenediammonium (en) and PEA, can achieve a bandgap as large as $1.9 \mathrm{eV} .^{58,59}$ The \{en $\mathrm{FASnI}_{3}$ PSCs with $25 \%$ en loading showed a bandgap of 1.9 $\mathrm{eV}$ and PCE of $2.34 \% .{ }^{58}$ Other lead-free alternatives, such as $\mathrm{MA}_{3} \mathrm{Bi}_{2} \mathrm{I}_{9}$ and $\mathrm{MA}_{3} \mathrm{Sb}_{2} \mathrm{I}_{9-\mathrm{x}} \mathrm{Cl}_{x}$, also demonstrated a PCE of $\sim 3 \%$ and good storage stability. ${ }^{60,61}$ However, there is still a large efficiency gap between lead-free WBG PSCs and lead-based WBG PSCs, which is a bottleneck for developing efficient leadfree PTSCs.

\section{ALL-PEROVSKITE TANDEMS}

In this section, we summarize advances made in the fabrication of all-perovskite tandems on the device level. Special emphasis is placed on the development of TRJs and approaches for fabricating $2 \mathrm{~T}$ all-perovskite tandems. An ideal TRJ should facilitate efficient recombination of the carriers emerging from the rear and front cells and protect the underlying WBG perovskite film from any solvent damage. Meanwhile, the TRJ should exhibit low electrical and optical losses and incur minimal processing costs.

Several TRJs have been incorporated into 2T PTSCs, and here, we discuss the representative ones. Zhao et al. used vacuum processing to stack layers of ultrathin $\mathrm{Ag}(1 \mathrm{~nm}) / \mathrm{MoO}_{x}(3 \mathrm{~nm}) /$ ITO $(\sim 120 \mathrm{~nm})$ as the TRJ, and a champion tandem cell based on this architecture showed a PCE of $21.0 \%$ (Figure $4 a-c) .{ }^{17}$ It has been proven that the contact properties can largely be improved by using a thin Ag layer. However, the thick ITO layer induces near-infrared parasitic absorption losses and causes shunting between subcells, which severely restricts upscaling PTSCs. Yang et al. reported a TRJ with reduced-thickness ITO on $\mathrm{SnO}_{2}$ (ALD processed; $\left.13 \mathrm{~nm}\right) / \mathrm{ITO}(\sim 10 \mathrm{~nm})$, resulting in a champion PCE of $23.0 \%$ (Figure $4 \mathrm{~d}-\mathrm{f}$ ). ${ }^{19}$ Lin et al. demonstrated a TRJ consisting of an ALD-SnO 2 layer $(\sim 20$ $\mathrm{nm}$ thick) and metallic gold $(\sim 1 \mathrm{~nm})$ (Figure $4 \mathrm{~g}, \mathrm{~h}){ }^{29} \mathrm{~A}$ thermally deposited ultrathin Au layer $(\sim 1 \mathrm{~nm})$ facilitated electron-hole recombination in the TRJ. Tandem cells without the ultrathin Au layer showed low FF values with S-shaped $J-V$ curves. Using ALD-SnO $2 / \mathrm{Au}$ as the TRJ improved the FF and yielded certified PCEs of $24.8 \%$ and $22.1 \%$ for small-area (0.049 $\mathrm{cm}^{2}$ ) and large-area devices $\left(1.05 \mathrm{~cm}^{2}\right)$, respectively (Figure $4 \mathrm{i}$ ). $\mathrm{Yu}$ et al. further simplified the interconnection layer between WBG and NBG cells using $\mathrm{C}_{60} / \mathrm{SnO}_{1.76}$ for $2 \mathrm{~T}$ PTSCs (Figure
$4 j-1)$, which made the device fabrication easier and prevented the parasitic absorption from ITO layer and HTL (PEDOT:PSS). ${ }^{62}$ The device architecture simplification is attributed to the ambipolar carrier transport nature of $\mathrm{SnO}_{2-x}$ layer deposited by ALD.

Palmstrom et al. indicated that ALD precursors can diffuse into chemically inert $\mathrm{C}_{60}$ layers, which can lead to nonuniform films. This effect can be prevented by using an ultrathin $(1 \mathrm{~nm})$ poly(ethylenimine) ethoxylated (PEIE) layer on top of the $\mathrm{C}_{60}$ layer; this added film can also serve as a nucleation layer for the ALD process (Figure $5 \mathrm{~b}) .^{63}$ Taking advantage of the hydroxyl and amine groups of the PEIE layer that are reactive to metalorganic ALD precursors, a conformal aluminum zinc oxide (AZO) layer was deposited as a TRJ. Both rigid and flexible PTSCs were fabricated with PCEs of $23.1 \%$ and $21.3 \%$, respectively (Figure $5 \mathrm{a}, \mathrm{c}$ ).

In addition to using solution-processed perovskite films and vacuum-evaporated TRJs as discussed above, an all-vacuumevaporation or all-solution-processing protocol has been explored. Vapor-phase deposition of absorbers or charge transport layers is highly attractive for large-area tandems because it enables precise control over thickness with nanometer accuracy, high uniformity of films without morphological defects such as pinholes, and no solvent damage to the bottom perovskite layer when processing the top perovskite layer. Ávila et al. reported a vacuum-deposition protocol for the fabrication of $\mathrm{MAPbI}_{3}-\mathrm{MAPbI}_{3}$ PTSCs with optically optimized (thickness tuned) perovskite layers and a TRJ (intrinsic ( TaTm), which was doped (TaTm: $\left.\mathrm{F}_{6}-\mathrm{TCNNQ}\right)$ to achieve a matched current and to minimize parasitic absorption losses. ${ }^{64}$ This $\mathrm{MAPbI}_{3}-$ $\mathrm{MAPbI}_{3}$ PTSC yielded a high $V_{\mathrm{OC}}$ of $2.30 \mathrm{~V}$ and a PCE of over $18 \%$. However, the development of thermally evaporated WBG and NBG PSCs is urgently needed to realize higher PCE outputs.

By contrast, solution-processable TRJs allow for upscaling PTSCs using vacuum-free deposition methods. However, it remains highly challenging to protect the underlying layers from the solvent used to process the layers above. McMeekin et al. replaced the commonly used DMF/DMSO solvent for the perovskite precursor with highly volatile acetonitrile $\left(\mathrm{CH}_{3} \mathrm{CN}\right)$ / methylamine $\left(\mathrm{CH}_{3} \mathrm{NH}_{2}\right)(\mathrm{ACN} / \mathrm{MA})$ and demonstrated fully solution-processed absorber, transporting, and TRJ layers (PEDOT:PSS/ITO nanoparticles) for monolithic PTSCs and triple-junction PSCs. ${ }^{65}$ Two-terminal double-junction tandems with $\mathrm{FA}_{0.83} \mathrm{Cs}_{0.17} \mathrm{~Pb}\left(\mathrm{Br}_{0.7} \mathrm{I}_{0.3}\right)_{3}(1.94 \mathrm{eV})$ and $\mathrm{MAPbI}_{3}(1.57 \mathrm{eV})$ subcells showed a PCE of $15 \%$, and as the first proof of concept, triple-junction tandems were demonstrated by further incorporating $\mathrm{MAPb}_{0.75} \mathrm{Sn}_{0.25} \mathrm{I}_{3}(1.34 \mathrm{eV})$ as the NBG layer. The triplejunction tandems showed $V_{\mathrm{OC}}$ values reaching $2.83 \mathrm{~V}$ and, 


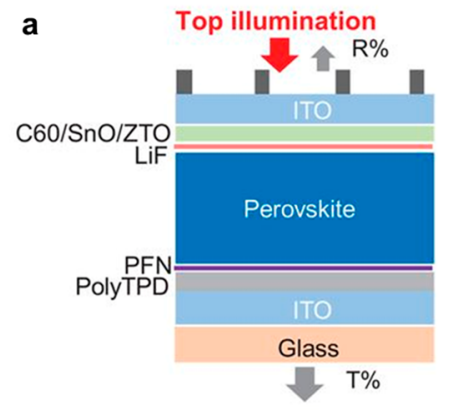

b

c

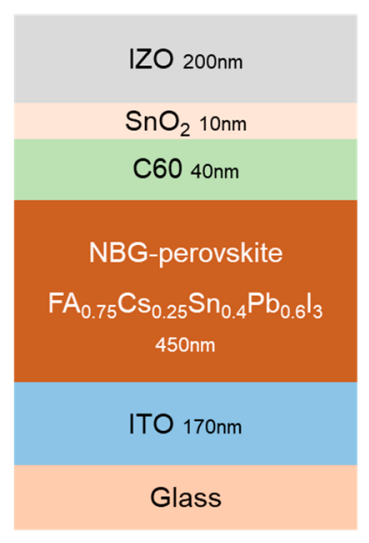

e

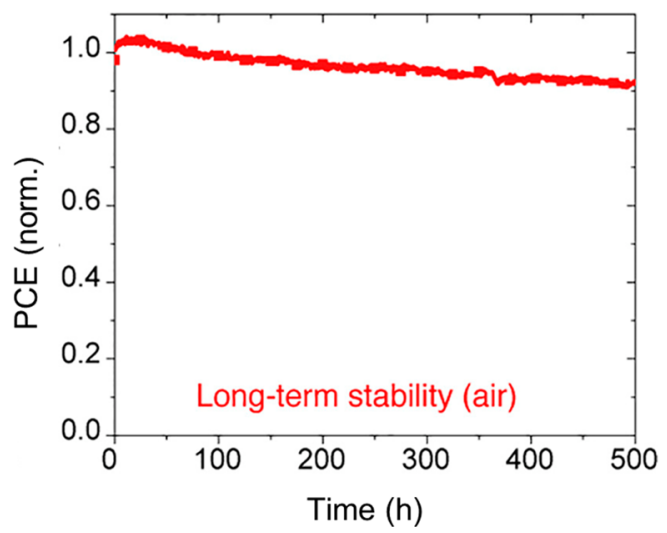

d
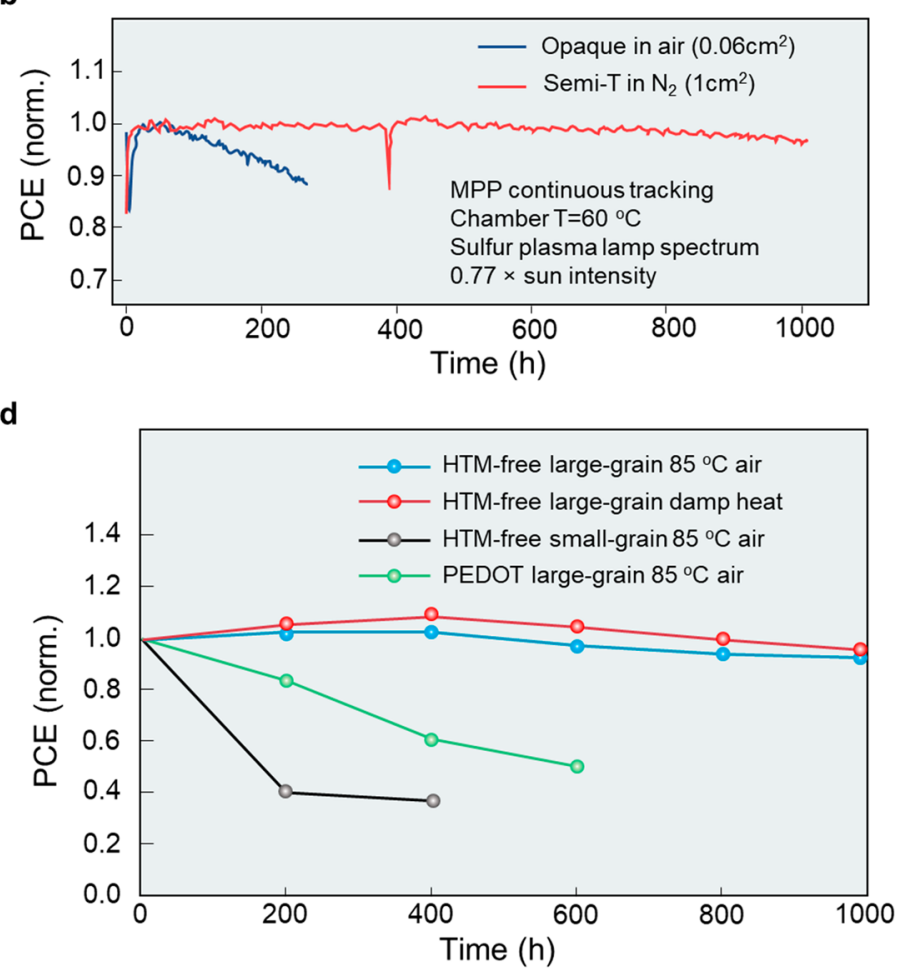

f

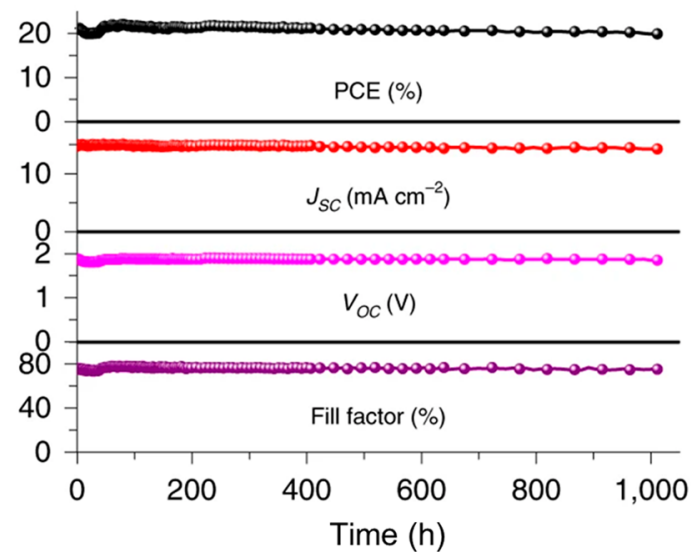

Figure 6. Device stability: environmental, thermal, and operational. (a) Architecture of semitransparent WBG triple-halide perovskite device. (b) Long-term stability of WBG triple-halide PSCs under illumination and thermal stress. Reproduced with permission from ref 40 . Copyright 2020 American Association for the Advancement of Science. (c) Architecture of NBG Pb-Sn perovskite device for thermal stability testing. (d) Normalized performance at $85^{\circ} \mathrm{C}$ in air (without encapsulation) or in damp heat (with glass-on-glass encapsulation) as a function of aging time for NBG $\mathrm{Pb}-\mathrm{Sn}$ perovskite devices. Reproduced with permission from ref 15. Copyright 2019 Nature Publishing Group. (e) Long-term stability of encapsulated PTSC under continuous light illumination in air. Reproduced with permission from ref 63. Copyright 2019 Cell Press. (f) Long-term stability of PTSC with $\mathrm{C}_{60} / \mathrm{SnO}_{1.76}$ interconnection layer under continuous light illumination at room temperature. Reproduced with permission from ref 62 . Copyright 2020 Nature Publishing Group.

through optical and electronic modeling, a predicted PCE of 26.7\%. All-solution-processed all-perovskite tandems open a new route for large-scale, low-cost, printable perovskite PVs.

\section{DEVICE STABILITY}

The light instability of WBG PSCs is one of the biggest challenges for their application in PTSCs. Increasing the crystallinity and grain size of these WBG perovskite films can improve their stability under 1-sun illumination. ${ }^{24,66}$ In addition to morphological modifications, compositional tuning can reduce phase-segregation pathways of WBG perovskite compounds. For example, a triple-halide ( $\mathrm{Cl}, \mathrm{Br}, \mathrm{I})$ WBG perovskite achieved by alloying an $\mathrm{I}-\mathrm{Br}$ mixed perovskite lattice with $\mathrm{Cl}$ showed higher resistance to illumination, without displaying a shift in the PL spectrum centroid (phase separation) under 10 sun equivalent illumination. Triple-halide WBG semitransparent top cells retained over $96 \%$ of their initial efficiency after $1000 \mathrm{~h}$ of MPP tracking at $60^{\circ} \mathrm{C}$ under a nitrogen atmosphere (Figure 6a,b). ${ }^{40}$ The mechanism underpinning the positive roles of $\mathrm{Cl}$ in suppressing phase separation was further revealed by Cho et al.; the authors demonstrated an increased activation energy for photoinduced halide segregation after $\mathrm{Cl}$ incorporation. $^{67}$ 
Additive engineering and defect passivation are also effective in suppressing phase segregation in WBG films and tin vacancies in NBG films, as discussed previously in detail and will thus not be expanded upon here.

NBG tin-lead alloyed perovskites have previously been observed to be extremely unstable in air because of tin oxidation, which presents an enormous obstacle to scaling up and successful operation under real-world conditions. Prasanna et al. comprehensively studied the influence of grain size and device architecture on the operational stability of $\mathrm{Pb}-\mathrm{Sn}$ NBG PSCs. It has been shown that the commonly used hole transport layer, PEDOT:PSS, reacts with $\mathrm{Pb}-\mathrm{Sn}$ NBG perovskites, worsening charge extraction and thermal stability. ${ }^{15}$ To avoid this reaction, an HTL-free device architecture was designed by removing PEDOT:PSS. Oxidative degradation of the $\mathrm{Pb}-\mathrm{Sn}$ mixed NBG perovskite $\mathrm{FA}_{0.75} \mathrm{Cs}_{0.25} \mathrm{Sn}_{0.4} \mathrm{~Pb}_{0.6} \mathrm{I}_{3}$ can be suppressed by increasing compactness and grain size, as degradation is initiated at and catalyzed by the grain boundaries. Taking these factors into consideration-large grain size, compactness, and tailored architecture design (HTL-free + IZO electrode (Figure 6c) - no efficiency losses were observed after $1000 \mathrm{~h}$ of stability testing at $85{ }^{\circ} \mathrm{C}$ in air without encapsulation. Encapsulated $\mathrm{Pb}-\mathrm{Sn}$ alloyed NBG devices also showed good damp heat stability $\left(85^{\circ} \mathrm{C}, 85 \%\right.$ relative humidity $)$, retaining $95 \%$ of their initial efficiency after $1000 \mathrm{~h}$ (Figure 6d). ${ }^{15}$ Moreover, a sputtered indium zinc oxide (IZO) was deposited as a capping electrode because it can prevent the diffusion of metal into the perovskite when using metal as the electrode. Another effective way to avoid the reaction with PEDOT:PSS is to coat a buffer layer on top of it. Yang et al. stacked a layer of poly(triarylamine) (PTAA) on top of the PEDOT:PSS layer, together forming the HTL. ${ }^{19}$ Using other alternative HTLs, such as $\mathrm{NiO}_{x}$ and dopant-free PTAA, can also improve the stability of NBG devices. ${ }^{68,69}$ Han et al. applied low-temperature solution-processed $\mathrm{NiO}_{x}$ as the HTL and the corresponding devices retained $95 \%$ of their initial efficiency after 102 days storage. ${ }^{68}$ Werner et al. achieved substantial improvement of thermal stability for NBG devices by using PTAA as HTL and such devices kept $80 \%$ of the initial efficiency after $4000 \mathrm{~h}$ at 85 ${ }^{\circ} \mathrm{C} .69$

The stability of tandems reflects the collective stability profiles of the WBG front subcell, charge transport layers, TRJ, and NBG rear subcell. Yang et al. reported a $T_{90}$ (time when the device degrades to $90 \%$ of its initial efficiency) value of $\sim 200 \mathrm{~h}$ for encapsulated tandem cells measured under ambient conditions and 1 sun illumination with MPP tracking. ${ }^{19}$ By limiting the Sn vacancies, Lin et al. achieved substantial progress in improving the stability and reported a $T_{90}$ of $463 \mathrm{~h}$ for the encapsulated tandem cells at MPP under 1 sun illumination in a nitrogen-filled environment. ${ }^{29}$ In addition to the strategies for improving the intrinsic stability of a tandem device, encapsulation plays a crucial role in protecting the device from external stimuli and enables decent long-term operational stability. Palmstrom et al. developed an encapsulation strategy for all-perovskite tandems using a combination of ALD-deposited alumina and an epoxysealed glass cover slide, achieving a $T_{90}$ of over $500 \mathrm{~h}$ under constant illumination, a constant load, and ambient conditions (Figure 6e). ${ }^{63} \mathrm{Yu}$ et al. ${ }^{62}$ reported champion PTSCs device stability under 1 sun illumination after $1000 \mathrm{~h}$; the device retained $94 \%$ of its initial PCE (Figure 6f). Multiple factors contributed to achieving this decent PTSC long-term stability, including suppressed phase separation in WBG perovskite by incorporation of a high percentage of Cs, less $\mathrm{Sn}$ content in NBG perovskite, and avoidance of the PEDOT:PSS reaction with NBG perovskite by using $\mathrm{C}_{60} / \mathrm{SnO}_{1.76}$ as the interconnection layer.

\section{CONCLUSION AND OUTLOOK}

In summary, we have comprehensively discussed the recent advances made in the fabrication of all-perovskite tandems, as well as summarized the strategies and underlying mechanisms for improving the efficiency and stability via a bottom-up approach-starting with the NBG and WBG subcells and ending with the TRJ and tandem device. Although a prosperous future can be foreseen, further research efforts are still needed to remove the obstacles to commercialization. To provide insight into the future development of this growing field, we highlight the following remaining challenges and future perspectives.

1. Large $V_{\mathrm{OC}}$ deficit of WBG subcells. Although substantial progress has been made in improving WBG PSCs in recent years, $V_{\mathrm{OC}}$ losses are still much higher compared with those of their $1.55 \mathrm{eV}$ PSC counterparts. A pertinent issue to address regarding this photovoltage bottleneck is understanding the types of defects that act as deep traps when comparing the WBG to the typical $1.55 \mathrm{eV}$ perovskites. The compositional heterogeneity and unique defect profiles of WBG perovskites must be uncovered to determine the origin of large $V_{\mathrm{OC}}$ losses and therefore to further guide strategies (e.g., composition engineering, additive engineering, and defect passivation) that can manage and minimize the trap density. Optimizing the charge extraction layers' energy levels relative to those of WBG perovskites is also important to boost the $V_{\mathrm{OC}}$.

2. Scalable fabrication of perovskite tandems. PTSCs are usually processed in a nitrogen glovebox by the spincoating method. Sn-based NBG perovskites are highly sensitive to ambient air. Very small concentrations of $\mathrm{Sn}^{4+}$ cause self-doping and can be detrimental to device performance and stability. This effect makes the mass fabrication of NBG perovskite films by scalable methods very challenging because the use of an inert atmosphere will raise expenses and complexity. Fabrication of allperovskite tandems via scalable methods is still rare. Thus, the exploration of scalable fabrication of both WBG and NBG perovskite films with large-area uniformity and high electronic quality will accelerate the transition of allperovskite tandems from the lab into the real world.

3. Improving the stability of PTSCs. PTSCs are complex systems with multiple components, each of which must possess good stability, including two perovskite layers, electrodes, several charge transport layers, and the interfaces generated by these components. Highly reactive combinations of PEDOT:PSS and $\mathrm{Pb}-\mathrm{Sn}$ NBG perovskites are still used in most high-performance allperovskite tandems, which poses a challenge to the longterm stability of all-perovskite tandems. HTL-free alternatives, alternative HTLs, and coatings on PEDOT:PSS can be further explored for use in all-perovskite tandems to avoid this reactivity issue. Transparent conductive oxide layers play key roles in stopping ion migration from diffusing to the metal electrode and preventing unfavorable reactions and formation of metal iodides. Utilizing a dopant-free charge transport layer would also help enhance device stability. 
4. Encapsulation of PTSCs passing strict international standards. The International Electrotechnical Commission testing standard IEC61215:2016 includes thermal cycling, damp heating, and humidity freeze tests. Under these stresses, gas-phase degradation products of unencapsulated perovskite films will escape from the perovskite lattice and be released into the surrounding environment. Recently, it has been shown that polymer/ glass stack pressure-tight encapsulation is effective in suppressing such outgassing. ${ }^{70}$ Moreover, harmful atmospheric stimuli $\left(\mathrm{O}_{2}\right.$ and $\left.\mathrm{H}_{2} \mathrm{O}\right)$ also accelerate the degradation of WBG and NBG perovskites. Thus, effective encapsulation to suppress perovskite outgassing and to isolate the components from external stimuli in the surrounding environment is crucial.

\section{AUTHOR INFORMATION}

\section{Corresponding Authors}

Edward H. Sargent - Department of Electrical and Computer Engineering, University of Toronto, Toronto, Ontario M5S 3G4, Canada; (1) orcid.org/0000-0003-0396-6495;

Email: ted.sargent@utoronto.ca

Osman M. Bakr - Division of Physical Sciences and Engineering, King Abdullah University of Science and Technology (KAUST), Thuwal 23955-6900, Saudi Arabia; 이잉.org/0000-00023428-1002; Email: osman.bakr@kaust.edu.sa

\section{Authors}

Xiaopeng Zheng - Division of Physical Sciences and Engineering, King Abdullah University of Science and Technology (KAUST), Thuwal 23955-6900, Saudi Arabia; 이이이.org/0000-00015061-3655

Abdullah Y. Alsalloum - Division of Physical Sciences and Engineering, King Abdullah University of Science and Technology (KAUST), Thuwal 23955-6900, Saudi Arabia; 다이.org/ 0000-0001-8988-1307

Yi Hou - Department of Electrical and Computer Engineering, University of Toronto, Toronto, Ontario M5S 3G4, Canada; (1) orcid.org/0000-0002-1532-816X

Complete contact information is available at: https://pubs.acs.org/10.1021/accountsmr.0c00017

\section{Author Contributions}

${ }^{\#}$ X.Z., A.Y.A., and Y.H. contributed equally to this work. Notes

The authors declare no competing financial interest.

\section{Biographies}

Xiaopeng Zheng received his Ph.D. in Materials Science and Engineering from King Abdullah University of Science and Technology (KAUST) in 2020. He is currently a postdoctoral researcher in Prof. Osman Bakr's research group at KAUST. His research focuses on perovskite photovoltaics and light-emitting diodes for clean-energy harvesting and displays.

Abdullah Y. Alsalloum completed his undergraduate studies in 2017 at MIT with a dual degree in Physics and Materials Science and Engineering. He then obtained his master's degree in 2019 from KAUST, where he joined Prof. Osman Bakr's group and worked on developing efficient monocrystalline and polycrystalline halide perovskite photovoltaics.
Yi Hou earned his Ph.D. from the University of Erlangen-Nuremberg in Germany in 2017. He is currently a postdoctoral fellow in the Prof. Edward Sargent group at the University of Toronto in Canada focusing on the investigation of optical and electronic properties of hybrid perovskite semiconductors. Dr. Yi Hou has been awarded the NUS Presidential Young Professorship (PYP) and will be joining National University of Singapore as an Assistant Professor in Fall 2020.

Edward H. Sargent holds the rank of University Professor in the Edward S. Rogers Sr. Department of Electrical and Computer Engineering at the University of Toronto. He holds the Canada Research Chair in Nanotechnology and also serves as Vice-President, Research and Innovation, and Strategic Initiatives, for the University of Toronto. His research focuses on renewable energy harvesting and storage with nanomaterials.

Osman M. Bakr holds a B.Sc. in Materials Science and Engineering from MIT (2003) and an M.S. and Ph.D. in Applied Physics from Harvard University (2009). He is currently Professor of Materials Science and Engineering at KAUST, Saudi Arabia. His research group focuses on the study of hybrid organic-inorganic materials; particularly, advancing their synthesis and self-assembly for applications in optoelectronics and catalysis.

\section{ACKNOWLEDGMENTS}

The authors acknowledge the funding support from King Abdullah University of Science and Technology (KAUST), the Ontario Research Fund-Research Excellence Program, and the Natural Sciences and Engineering Research Council of Canada (NSERC).

\section{REFERENCES}

(1) Shi, D.; Adinolfi, V.; Comin, R.; Yuan, M.; Alarousu, E.; Buin, A.; Chen, Y.; Hoogland, S.; Rothenberger, A.; Katsiev, K.; Losovyj, Y.; Zhang, X.; Dowben, P. A.; Mohammed, O. F.; Sargent, E. H.; Bakr, O. M. Low trap-state density and long carrier diffusion in organolead trihalide perovskite single crystals. Science 2015, 347, 519-522.

(2) Dong, Q.; Fang, Y.; Shao, Y.; Mulligan, P.; Qiu, J.; Cao, L.; Huang, J. Electron-hole diffusion lengths $>175 \mu \mathrm{m}$ in solution-grown $\mathrm{CH}_{3} \mathrm{NH}_{3} \mathrm{PbI}_{3}$ single crystals. Science 2015, 347, 967-970.

(3) Stranks, S. D.; Eperon, G. E.; Grancini, G.; Menelaou, C.; Alcocer, M. J. P.; Leijtens, T.; Herz, L. M.; Petrozza, A.; Snaith, H. J. ElectronHole Diffusion Lengths Exceeding 1 Micrometer in an Organometal Trihalide Perovskite Absorber. Science 2013, 342, 341-344.

(4) Yin, W.-J.; Shi, T.; Yan, Y. Unusual defect physics in $\mathrm{CH}_{3} \mathrm{NH}_{3} \mathrm{PbI}_{3}$ perovskite solar cell absorber. Appl. Phys. Lett. 2014, 104, No. 063903.

(5) Deng, Y.; Zheng, X.; Bai, Y.; Wang, Q.; Zhao, J.; Huang, J. Surfactant-controlled ink drying enables high-speed deposition of perovskite films for efficient photovoltaic modules. Nat. Energy 2018, 3, $560-566$.

(6) Tan, H.; Jain, A.; Voznyy, O.; Lan, X.; García de Arquer, F. P.; Fan, J. Z.; Quintero-Bermudez, R.; Yuan, M.; Zhang, B.; Zhao, Y.; Fan, F.; Li, P.; Quan, L. N.; Zhao, Y.; Lu, Z.-H.; Yang, Z.; Hoogland, S.; Sargent, E. $\mathrm{H}$. Efficient and stable solution-processed planar perovskite solar cells via contact passivation. Science 2017, 355, 722-726.

(7) Kojima, A.; Teshima, K.; Shirai, Y.; Miyasaka, T. Organometal halide perovskites as visible-light sensitizers for photovoltaic cells. J. Am. Chem. Soc. 2009, 131, 6050-6051.

(8) National Renewable Energy Laboratory, best research-cell efficiencies (2020). www.nrel.gov/pv/assets/pdfs/best-research-cellefficiencies.20200406.pdf.

(9) Leijtens, T.; Bush, K. A.; Prasanna, R.; McGehee, M. D. Opportunities and challenges for tandem solar cells using metal halide perovskite semiconductors. Nat. Energy 2018, 3, 828-838.

(10) Eperon, G. E.; Hörantner, M. T.; Snaith, H. J. Metal halide perovskite tandem and multiple-junction photovoltaics. Nat. Rev. Chem. 2017, 1, No. 0095. 
(11) Wang, Y.; Zhang, M.; Xiao, K.; Lin, R.; Luo, X.; Han, Q.; Tan, H. Recent progress in developing efficient monolithic all-perovskite tandem solar cells. J. Semicond. 2020, 41, No. 051201.

(12) Hörantner, M. T.; Leijtens, T.; Ziffer, M. E.; Eperon, G. E.; Christoforo, M. G.; McGehee, M. D.; Snaith, H. J. The Potential of Multijunction Perovskite Solar Cells. ACS Energy Lett. 2017, 2, 25062513.

(13) Chen, M.; Ju, M.-G.; Garces, H. F.; Carl, A. D.; Ono, L. K.; Hawash, Z.; Zhang, Y.; Shen, T.; Qi, Y.; Grimm, R. L.; Pacifici, D.; Zeng, X. C.; Zhou, Y.; Padture, N. P. Highly stable and efficient allinorganic lead-free perovskite solar cells with native-oxide passivation. Nat. Commun. 2019, 10, 16.

(14) Yang, Z.; Rajagopal, A.; Chueh, C.-C.; Jo, S. B.; Liu, B.; Zhao, T.; Jen, A. K.-Y. Stable Low-Bandgap $\mathrm{Pb}-\mathrm{Sn}$ Binary Perovskites for Tandem Solar Cells. Adv. Mater. 2016, 28, 8990-8997.

(15) Prasanna, R.; Leijtens, T.; Dunfield, S. P.; Raiford, J. A.; Wolf, E. J.; Swifter, S. A.; Werner, J.; Eperon, G. E.; de Paula, C.; Palmstrom, A. F.; Boyd, C. C.; van Hest, M. F. A. M.; Bent, S. F.; Teeter, G.; Berry, J.J.; McGehee, M. D. Design of low bandgap tin-lead halide perovskite solar cells to achieve thermal, atmospheric and operational stability. Nat. Energy 2019, 4, 939-947.

(16) Zhao, D.; Yu, Y.; Wang, C.; Liao, W.; Shrestha, N.; Grice, C. R.; Cimaroli, A. J.; Guan, L.; Ellingson, R. J.; Zhu, K.; Zhao, X.; Xiong, R.G.; Yan, Y. Low-bandgap mixed tin-lead iodide perovskite absorbers with long carrier lifetimes for all-perovskite tandem solar cells. Nat. Energy 2017, 2, 17018.

(17) Zhao, D.; Chen, C.; Wang, C.; Junda, M. M.; Song, Z.; Grice, C. R.; Yu, Y.; Li, C.; Subedi, B.; Podraza, N. J.; Zhao, X.; Fang, G.; Xiong, R.-G.; Zhu, K.; Yan, Y. Efficient two-terminal all-perovskite tandem solar cells enabled by high-quality low-bandgap absorber layers. Nat. Energy 2018, 3, 1093-1100.

(18) Lin, Y.; Chen, B.; Fang, Y.; Zhao, J.; Bao, C.; Yu, Z.; Deng, Y.; Rudd, P. N.; Yan, Y.; Yuan, Y.; Huang, J. Excess charge-carrier induced instability of hybrid perovskites. Nat. Commun. 2018, 9, 4981.

(19) Yang, Z.; Yu, Z.; Wei, H.; Xiao, X.; Ni, Z.; Chen, B.; Deng, Y.; Habisreutinger, S. N.; Chen, X.; Wang, K.; Zhao, J.; Rudd, P. N.; Berry, J. J.; Beard, M. C.; Huang, J. Enhancing electron diffusion length in narrow-bandgap perovskites for efficient monolithic perovskite tandem solar cells. Nat. Commun. 2019, 10, 4498.

(20) Hao, F.; Stoumpos, C. C.; Chang, R. P. H.; Kanatzidis, M. G. Anomalous Band Gap Behavior in Mixed $\mathrm{Sn}$ and $\mathrm{Pb}$ Perovskites Enables Broadening of Absorption Spectrum in Solar Cells. J. Am. Chem. Soc. 2014, 136, 8094-8099.

(21) Rajagopal, A.; Yang, Z.; Jo, S. B.; Braly, I. L.; Liang, P. W.; Hillhouse, H. W.; Jen, A. K. Highly Efficient Perovskite-Perovskite Tandem Solar Cells Reaching 80\% of the Theoretical Limit in Photovoltage. Adv. Mater. 2017, 29, 1702140.

(22) Kumar, M. H.; Dharani, S.; Leong, W. L.; Boix, P. P.; Prabhakar, R. R.; Baikie, T.; Shi, C.; Ding, H.; Ramesh, R.; Asta, M.; Graetzel, M.; Mhaisalkar, S. G.; Mathews, N. Lead-free halide perovskite solar cells with high photocurrents realized through vacancy modulation. Adv. Mater. 2014, 26, 7122-7127.

(23) Eperon, G. E.; Leijtens, T.; Bush, K. A.; Prasanna, R.; Green, T.; Wang, J. T.; McMeekin, D. P.; Volonakis, G.; Milot, R. L.; May, R.; Palmstrom, A.; Slotcavage, D. J.; Belisle, R. A.; Patel, J. B.; Parrott, E. S.; Sutton, R. J.; Ma, W.; Moghadam, F.; Conings, B.; Babayigit, A.; Boyen, H. G.; Bent, S.; Giustino, F.; Herz, L. M.; Johnston, M. B.; McGehee, M. D.; Snaith, H. J. Perovskite-perovskite tandem photovoltaics with optimized band gaps. Science 2016, 354, 861-865.

(24) Leijtens, T.; Prasanna, R.; Bush, K. A.; Eperon, G. E.; Raiford, J. A.; Gold-Parker, A.; Wolf, E. J.; Swifter, S. A.; Boyd, C. C.; Wang, H. P.; Toney, M. F.; Bent, S. F.; McGehee, M. D. Tin-lead halide perovskites with improved thermal and air stability for efficient all-perovskite tandem solar cells. Sustain Energ Fuels 2018, 2, 2450-2459.

(25) Shao, S.; Cui, Y.; Duim, H.; Qiu, X.; Dong, J.; ten Brink, G. H.; Portale, G.; Chiechi, R. C.; Zhang, S.; Hou, J.; Loi, M. A. Enhancing the Performance of the Half Tin and Half Lead Perovskite Solar Cells by Suppression of the Bulk and Interfacial Charge Recombination. Adv. Mater. 2018, 30, 1803703.
(26) Tong, J.; Song, Z.; Kim, D. H.; Chen, X.; Chen, C.; Palmstrom, A. F.; Ndione, P. F.; Reese, M. O.; Dunfield, S. P.; Reid, O. G.; Liu, J.; Zhang, F.; Harvey, S. P.; Li, Z.; Christensen, S. T.; Teeter, G.; Zhao, D.; Al-Jassim, M. M.; van Hest, M.; Beard, M. C.; Shaheen, S. E.; Berry, J. J.; Yan, Y.; Zhu, K. Carrier lifetimes of $>1 \mu \mathrm{s}$ in $\mathrm{Sn}-\mathrm{Pb}$ perovskites enable efficient all-perovskite tandem solar cells. Science 2019, 364, 475-479.

(27) Wei, M.; Xiao, K.; Walters, G.; Lin, R.; Zhao, Y.; Saidaminov, M. I.; Todorovic, P.; Johnston, A.; Huang, Z.; Chen, H.; Li, A.; Zhu, J.; Yang, Z.; Wang, Y. K.; Proppe, A. H.; Kelley, S. O.; Hou, Y.; Voznyy, O.; Tan, H.; Sargent, E. H. Combining Efficiency and Stability in Mixed Tin-Lead Perovskite Solar Cells by Capping Grains with an Ultrathin 2D Layer. Adv. Mater. 2020, 32, No. e1907058.

(28) Gu, F. D.; Ye, S. Y.; Zhao, Z. R.; Rao, H. X.; Liu, Z. W.; Bian, Z. Q.; Huang, C. H. Improving Performance of Lead-Free Formamidinium Tin Triiodide Perovskite Solar Cells by Tin Source Purification. Sol Rrl 2018, 2, 1800136.

(29) Lin, R.; Xiao, K.; Qin, Z.; Han, Q.; Zhang, C.; Wei, M.; Saidaminov, M. I.; Gao, Y.; Xu, J.; Xiao, M.; Li, A.; Zhu, J.; Sargent, E. H.; Tan, H. Monolithic all-perovskite tandem solar cells with $24.8 \%$ efficiency exploiting comproportionation to suppress $\mathrm{Sn}$ (ii) oxidation in precursor ink. Nat. Energy 2019, 4, 864-873.

(30) Green, M. A.; Dunlop, E. D.; Hohl-Ebinger, J.; Yoshita, M.; Kopidakis, N.; Hao, X. Solar cell efficiency tables (version 56). Prog. Photovoltaics 2020, 28, 629-638.

(31) Nakamura, T.; Yakumaru, S.; Truong, M. A.; Kim, K.; Liu, J.; Hu, S.; Otsuka, K.; Hashimoto, R.; Murdey, R.; Sasamori, T.; Kim, H. D.; Ohkita, H.; Handa, T.; Kanemitsu, Y.; Wakamiya, A. Sn(IV)-free tin perovskite films realized by in situ $\mathrm{Sn}(0)$ nanoparticle treatment of the precursor solution. Nat. Commun. 2020, 11, 3008.

(32) Meng, X.; Wang, Y.; Lin, J.; Liu, X.; He, X.; Barbaud, J.; Wu, T.; Noda, T.; Yang, X.; Han, L. Surface-Controlled Oriented Growth of $\mathrm{FASnI}_{3}$ Crystals for Efficient Lead-free Perovskite Solar Cells. Joule 2020, 4, 902-912.

(33) Jiang, X.; Wang, F.; Wei, Q.; Li, H.; Shang, Y.; Zhou, W.; Wang, C.; Cheng, P.; Chen, Q.; Chen, L.; Ning, Z. Ultra-high open-circuit voltage of tin perovskite solar cells via an electron transporting layer design. Nat. Commun. 2020, 11, 1245.

(34) Shao, S.; Liu, J.; Portale, G.; Fang, H.-H.; Blake, G. R.; ten Brink, G. H.; Koster, L. J. A.; Loi, M. A. Highly Reproducible Sn-Based Hybrid Perovskite Solar Cells with 9\% Efficiency. Adv. Energy Mater. 2018, 8, 1702019.

(35) Chen, M.; Dong, Q.; Eickemeyer, F. T.; Liu, Y.; Dai, Z.; Carl, A. D.; Bahrami, B.; Chowdhury, A. H.; Grimm, R. L.; Shi, Y.; Qiao, Q.; Zakeeruddin, S. M.; Grätzel, M.; Padture, N. P. High-Performance Lead-Free Solar Cells Based on Tin-Halide Perovskite Thin Films Functionalized by a Divalent Organic Cation. ACS Energy Lett. 2020, 5, 2223-2230.

(36) Tan, H.; Che, F.; Wei, M.; Zhao, Y.; Saidaminov, M. I.; Todorović, P.; Broberg, D.; Walters, G.; Tan, F.; Zhuang, T.; Sun, B.; Liang, Z.; Yuan, H.; Fron, E.; Kim, J.; Yang, Z.; Voznyy, O.; Asta, M.; Sargent, E. H. Dipolar cations confer defect tolerance in wide-bandgap metal halide perovskites. Nat. Commun. 2018, 9, 3100.

(37) Kim, J.; Saidaminov, M. I.; Tan, H.; Zhao, Y.; Kim, Y.; Choi, J.; Jo, J. W.; Fan, J.; Quintero-Bermudez, R.; Yang, Z.; Quan, L. N.; Wei, M.; Voznyy, O.; Sargent, E. H. Amide-Catalyzed Phase-Selective Crystallization Reduces Defect Density in Wide-Bandgap Perovskites. Adv. Mater. 2018, 30, 1706275.

(38) Yang, M.; Kim, D. H.; Yu, Y.; Li, Z.; Reid, O. G.; Song, Z.; Zhao, D.; Wang, C.; Li, L.; Meng, Y.; Guo, T.; Yan, Y.; Zhu, K. Effect of nonstoichiometric solution chemistry on improving the performance of wide-bandgap perovskite solar cells. Materials Today Energy 2018, 7, 232-238.

(39) Suri, M.; Hazarika, A.; Larson, B. W.; Zhao, Q.; Vallés-Pelarda, M.; Siegler, T. D.; Abney, M. K.; Ferguson, A. J.; Korgel, B. A.; Luther, J. M. Enhanced Open-Circuit Voltage of Wide-Bandgap Perovskite Photovoltaics by Using Alloyed $\left(\mathrm{FA}_{1-\mathrm{x}} \mathrm{Cs}_{\mathrm{x}}\right) \mathrm{Pb}\left(\mathrm{I}_{1-\mathrm{x}} \mathrm{Br}_{\mathrm{x}}\right)_{3}$ Quantum Dots. ACS Energy Letters 2019, 4, 1954-1960.

(40) Xu, J.; Boyd, C. C.; Yu, Z. J.; Palmstrom, A. F.; Witter, D. J.; Larson, B. W.; France, R. M.; Werner, J.; Harvey, S. P.; Wolf, E. J.; 
Weigand, W.; Manzoor, S.; van Hest, M. F. A. M.; Berry, J. J.; Luther, J. M.; Holman, Z. C.; McGehee, M. D. Triple-halide wide-band gap perovskites with suppressed phase segregation for efficient tandems. Science 2020, 367, 1097-1104.

(41) Zheng, X.; Troughton, J.; Gasparini, N.; Lin, Y.; Wei, M.; Hou, Y.; Liu, J.; Song, K.; Chen, Z.; Yang, C.; Turedi, B.; Alsalloum, A. Y.; Pan, J.; Chen, J.; Zhumekenov, A. A.; Anthopoulos, T. D.; Han, Y.; Baran, D.; Mohammed, O. F.; Sargent, E. H.; Bakr, O. M. Quantum Dots Supply Bulk- and Surface-Passivation Agents for Efficient and Stable Perovskite Solar Cells. Joule 2019, 3, 1963-1976.

(42) Yu, Y.; Wang, C.; Grice, C. R.; Shrestha, N.; Zhao, D.; Liao, W.; Guan, L.; Awni, R. A.; Meng, W.; Cimaroli, A. J.; Zhu, K.; Ellingson, R. J.; Yan, Y. Synergistic Effects of Lead Thiocyanate Additive and Solvent Annealing on the Performance of Wide-Bandgap Perovskite Solar Cells. ACS Energy Lett. 2017, 2, 1177-1182.

(43) Chen, C.; Song, Z.; Xiao, C.; Zhao, D.; Shrestha, N.; Li, C.; Yang, G.; Yao, F.; Zheng, X.; Ellingson, R. J.; Jiang, C.-S.; Al-Jassim, M.; Zhu, K.; Fang, G.; Yan, Y. Achieving a high open-circuit voltage in inverted wide-bandgap perovskite solar cells with a graded perovskite homojunction. Nano Energy 2019, 61, 141-147.

(44) Gharibzadeh, S.; Abdollahi Nejand, B.; Jakoby, M.; Abzieher, T.; Hauschild, D.; Moghadamzadeh, S.; Schwenzer, J. A.; Brenner, P.; Schmager, R.; Haghighirad, A. A.; Weinhardt, L.; Lemmer, U.; Richards, B. S.; Howard, I. A.; Paetzold, U. W. Record Open-Circuit Voltage Wide-Bandgap Perovskite Solar Cells Utilizing 2D/3D Perovskite Heterostructure. Adv. Energy Mater. 2019, 9, 1803699.

(45) Kim, D. H.; Muzzillo, C. P.; Tong, J.; Palmstrom, A. F.; Larson, B. W.; Choi, C.; Harvey, S. P.; Glynn, S.; Whitaker, J. B.; Zhang, F.; Li, Z.; Lu, H.; van Hest, M. F. A. M.; Berry, J. J.; Mansfield, L. M.; Huang, Y.; Yan, Y.; Zhu, K. Bimolecular Additives Improve Wide-Band-Gap Perovskites for Efficient Tandem Solar Cells with CIGS. Joule 2019, 3, 1734-1745.

(46) Kim, D.; Jung, H. J.; Park, I. J.; Larson, B. W.; Dunfield, S. P.; Xiao, C.; Kim, J.; Tong, J.; Boonmongkolras, P.; Ji, S. G.; Zhang, F.; Pae, S. R.; Kim, M.; Kang, S. B.; Dravid, V.; Berry, J. J.; Kim, J. Y.; Zhu, K.; Kim, D. H.; Shin, B. Efficient, stable silicon tandem cells enabled by anion-engineered wide-bandgap perovskites. Science 2020, 368, 155.

(47) Ye, J. Y.; Tong, J.; Hu, J.; Xiao, C.; Lu, H.; Dunfield, S. P.; Kim, D. H.; Chen, X.; Larson, B. W.; Hao, J.; Wang, K.; Zhao, Q.; Chen, Z.; Hu, H.; You, W.; Berry, J. J.; Zhang, F.; Zhu, K. Enhancing Charge Transport of 2D Perovskite Passivation Agent for Wide-Bandgap Perovskite Solar Cells Beyond 21\%. Sol Rrl 2020, 4, 2000082.

(48) Chen, C.; Song, Z.; Xiao, C.; Awni, R. A.; Yao, C.; Shrestha, N.; Li, C.; Bista, S. S.; Zhang, Y.; Chen, L.; Ellingson, R. J.; Jiang, C.-S.; AlJassim, M.; Fang, G.; Yan, Y. Arylammonium-Assisted Reduction of the Open-Circuit Voltage Deficit in Wide-Bandgap Perovskite Solar Cells: The Role of Suppressed Ion Migration. ACS Energy Lett. 2020, 5, $2560-2568$.

(49) Doherty, T. A. S.; Winchester, A. J.; Macpherson, S.; Johnstone, D. N.; Pareek, V.; Tennyson, E. M.; Kosar, S.; Kosasih, F. U.; Anaya, M.; Abdi-Jalebi, M.; Andaji-Garmaroudi, Z.; Wong, E. L.; Madéo, J.; Chiang, Y.-H.; Park, J.-S.; Jung, Y.-K.; Petoukhoff, C. E.; Divitini, G.; Man, M. K. L.; Ducati, C.; Walsh, A.; Midgley, P. A.; Dani, K. M.; Stranks, S. D. Performance-limiting nanoscale trap clusters at grain junctions in halide perovskites. Nature 2020, 580, 360-366.

(50) Chen, B.; Yu, Z.; Liu, K.; Zheng, X.; Liu, Y.; Shi, J.; Spronk, D.; Rudd, P. N.; Holman, Z.; Huang, J. Grain Engineering for Perovskite/ Silicon Monolithic Tandem Solar Cells with Efficiency of 25.4\%. Joule 2019, 3, 177-190.

(51) Ni, Z.; Bao, C.; Liu, Y.; Jiang, Q.; Wu, W.-Q.; Chen, S.; Dai, X.; Chen, B.; Hartweg, B.; Yu, Z.; Holman, Z.; Huang, J. Resolving spatial and energetic distributions of trap states in metal halide perovskite solar cells. Science 2020, 367, 1352-1358.

(52) Luo, D.; Su, R.; Zhang, W.; Gong, Q.; Zhu, R. Minimizing nonradiative recombination losses in perovskite solar cells. Nat. Rev. Mater. 2020, 5, 44-60.

(53) Alsalloum, A. Y.; Turedi, B.; Zheng, X.; Mitra, S.; Zhumekenov, A. A.; Lee, K. J.; Maity, P.; Gereige, I.; AlSaggaf, A.; Roqan, I. S.; Mohammed, O. F.; Bakr, O. M. Low-Temperature Crystallization
Enables 21.9\% Efficient Single-Crystal $\mathrm{MAPbI}_{3}$ Inverted Perovskite Solar Cells. ACS Energy Lett. 2020, 5, 657-662.

(54) Hou, Y.; Aydin, E.; De Bastiani, M.; Xiao, C.; Isikgor, F. H.; Xue, D.-J.; Chen, B.; Chen, H.; Bahrami, B.; Chowdhury, A. H.; Johnston, A.; Baek, S.-W.; Huang, Z.; Wei, M.; Dong, Y.; Troughton, J.; Jalmood, R.; Mirabelli, A. J.; Allen, T. G.; Van Kerschaver, E.; Saidaminov, M. I.; Baran, D.; Qiao, Q.; Zhu, K.; De Wolf, S.; Sargent, E. H. Efficient tandem solar cells with solution-processed perovskite on textured crystalline silicon. Science 2020, 367, 1135-1140.

(55) Zheng, X.; Hou, Y.; Bao, C.; Yin, J.; Yuan, F.; Huang, Z.; Song, K.; Liu, J.; Troughton, J.; Gasparini, N.; Zhou, C.; Lin, Y.; Xue, D.-J.; Chen, B.; Johnston, A. K.; Wei, N.; Hedhili, M. N.; Wei, M.; Alsalloum, A. Y.; Maity, P.; Turedi, B.; Yang, C.; Baran, D.; Anthopoulos, T. D.; Han, Y.; Lu, Z.-H.; Mohammed, O. F.; Gao, F.; Sargent, E. H.; Bakr, O. M. Managing grains and interfaces via ligand anchoring enables $22.3 \%$ efficiency inverted perovskite solar cells. Nat. Energy 2020, 5, 131-140.

(56) Lin, Y.; Chen, B.; Zhao, F.; Zheng, X.; Deng, Y.; Shao, Y.; Fang, Y.; Bai, Y.; Wang, C.; Huang, J. Matching Charge Extraction Contact for Wide-Bandgap Perovskite Solar Cells. Adv. Mater. 2017, 29, 1700607.

(57) Khadka, D. B.; Shirai, Y.; Yanagida, M.; Noda, T.; Miyano, K. Tailoring the Open-Circuit Voltage Deficit of Wide-Band-Gap Perovskite Solar Cells Using Alkyl Chain-Substituted Fullerene Derivatives. ACS Appl. Mater. Interfaces 2018, 10, 22074-22082.

(58) Ke, W.; Stoumpos, C. C.; Zhu, M.; Mao, L.; Spanopoulos, I.; Liu, J.; Kontsevoi, O. Y.; Chen, M.; Sarma, D.; Zhang, Y.; Wasielewski, M. R.; Kanatzidis, M. G. Enhanced photovoltaic performance and stability with a new type of hollow 3D perovskite $\{$ en $\} \mathrm{FASnI}_{3} . S c i . A d v .2017,3$, No. e1701293.

(59) Lanzetta, L.; Marin-Beloqui, J. M.; Sanchez-Molina, I.; Ding, D.; Haque, S. A. Two-Dimensional Organic Tin Halide Perovskites with Tunable Visible Emission and Their Use in Light-Emitting Devices. ACS Energy Lett. 2017, 2, 1662-1668.

(60) Jain, S. M.; Edvinsson, T.; Durrant, J. R. Green fabrication of stable lead-free bismuth based perovskite solar cells using a non-toxic solvent. Commun. Chem. 2019, 2, 91.

(61) Yang, Y.; Liu, C.; Cai, M.; Liao, Y.; Ding, Y.; Ma, S.; Liu, X.; Guli, M.; Dai, S.; Nazeeruddin, M. K. Dimension-Controlled Growth of Antimony-Based Perovskite-like Halides for Lead-Free and Semitransparent Photovoltaics. ACS Appl. Mater. Interfaces 2020, 12, 17062-17069.

(62) Yu, Z.; Yang, Z.; Ni, Z.; Shao, Y.; Chen, B.; Lin, Y.; Wei, H.; Yu, Z. J.; Holman, Z.; Huang, J. Simplified interconnection structure based on $\mathrm{C}_{60} / \mathrm{SnO}_{2-\mathrm{x}}$ for all-perovskite tandem solar cells. Nat. Energy 2020, 5, 657.

(63) Palmstrom, A. F.; Eperon, G. E.; Leijtens, T.; Prasanna, R.; Habisreutinger, S. N.; Nemeth, W.; Gaulding, E. A.; Dunfield, S. P.; Reese, M.; Nanayakkara, S.; Moot, T.; Werner, J.; Liu, J.; To, B.; Christensen, S. T.; McGehee, M. D.; van Hest, M. F. A. M.; Luther, J. M.; Berry, J. J.; Moore, D. T. Enabling Flexible All-Perovskite Tandem Solar Cells. Joule 2019, 3, 2193-2204.

(64) Ávila, J.; Momblona, C.; Boix, P.; Sessolo, M.; Anaya, M.; Lozano, G.; Vandewal, K.; Míguez, H.; Bolink, H. J. High voltage vacuum-deposited $\mathrm{CH}_{3} \mathrm{NH}_{3} \mathrm{PbI}_{3}-\mathrm{CH}_{3} \mathrm{NH}_{3} \mathrm{PbI}_{3}$ tandem solar cells. Energy Environ. Sci. 2018, 11, 3292-3297.

(65) McMeekin, D. P.; Mahesh, S.; Noel, N. K.; Klug, M. T.; Lim, J.; Warby, J. H.; Ball, J. M.; Herz, L. M.; Johnston, M. B.; Snaith, H. J. Solution-Processed All-Perovskite Multi-junction Solar Cells. Joule 2019, 3, 387-401.

(66) Hu, M.; Bi, C.; Yuan, Y.; Bai, Y.; Huang, J. Stabilized Wide Bandgap $\mathrm{MAPbBr}_{\mathrm{x}} \mathrm{I}_{3-\mathrm{x}}$ Perovskite by Enhanced Grain Size and Improved Crystallinity. Adv. Sci. 2016, 3, 1500301.

(67) Cho, J. S.; Kamat, P. V. How Chloride Suppresses Photoinduced Phase Segregation in Mixed Halide Perovskites. Chem. Mater. 2020, 32, $6206-6212$.

(68) Han, Q.; Wei, Y.; Lin, R.; Fang, Z.; Xiao, K.; Luo, X.; Gu, S.; Zhu, J.; Ding, L.; Tan, H. Low-temperature processed inorganic hole transport layer for efficient and stable mixed $\mathrm{Pb}-\mathrm{Sn}$ low-bandgap perovskite solar cells. Sci. Bull. 2019, 64, 1399. 
(69) Werner, J.; Moot, T.; Gossett, T. A.; Gould, I. E.; Palmstrom, A. F.; Wolf, E. J.; Boyd, C. C.; van Hest, M. F. A. M.; Luther, J. M.; Berry, J. J.; McGehee, M. D. Improving Low-Bandgap Tin-Lead Perovskite Solar Cells via Contact Engineering and Gas Quench Processing. ACS Energy Lett. 2020, 5, 1215-1223.

(70) Shi, L.; Bucknall, M. P.; Young, T. L.; Zhang, M.; Hu, L.; Bing, J.; Lee, D. S.; Kim, J.; Wu, T.; Takamure, N.; McKenzie, D. R.; Huang, S.; Green, M. A.; Ho-Baillie, A. W. Y. Gas chromatography-mass spectrometry analyses of encapsulated stable perovskite solar cells. Science 2020, 368, eaba2412. 